\title{
Activation of the UNC5B receptor by Netrin-1 inhibits sprouting angiogenesis
}

\author{
Bruno Larrivée, ${ }^{1,2,10}$ Catarina Freitas, ${ }^{1,2,10}$ Marc Trombe, ${ }^{1,2,10}$ Xiang Lv, ${ }^{1,2,11}$ Benjamin DeLafarge, ${ }^{1,2}$ \\ Li Yuan, ${ }^{1,2,12}$ Karine Bouvrée, ${ }^{1,2}$ Christiane Bréant, ${ }^{1,2}$ Raquel Del Toro, ${ }^{1,2}$ Nicolas Bréchot, ${ }^{1,2}$ \\ Stéphane Germain, ${ }^{1,2,3}$ Françoise Bono, ${ }^{4}$ Frédérique Dol, ${ }^{4}$ Filip Claes, ${ }^{5,6}$ Christian Fischer, ${ }^{5,6}$ \\ Monica Autiero, ${ }^{5,6}$ Jean-Léon Thomas, ${ }^{7,8}$ Peter Carmeliet,, ${ }^{5,6}$ Marc Tessier-Lavigne, ${ }^{9}$ \\ and Anne Eichmann ${ }^{1,2,13}$
}

${ }^{1}$ Institut National de la Santé et de la Recherche Médicale (INSERM) U833, F-75005 Paris, France; ${ }^{2}$ Collège de France, F-75005 Paris, France; ${ }^{3}$ Service d'Hématologie Biologique A-AP-HP-Hôpital Européen Georges Pompidou, F-75015 Paris, France; ${ }^{4}$ Sanofi-Aventis, F31036 Toulouse Cedex, France; ${ }^{5}$ The Center for Transgene Technology and Gene Therapy, K.U. Leuven, Leuven B-3000, Belgium; ${ }^{6}$ The Department of Transgene Technology and Gene Therapy, VIB, Leuven B-3000, Belgium; ${ }^{7}$ INSERM U711, F-75013 Paris, France; ${ }^{8}$ Université Pierre et Marie Curie, Faculté de Médecine Pitié Salpétrière, IFR 70, F-75005 Paris, France; ${ }^{9}$ Genentech Inc., South San Francisco, California 94080, USA

\begin{abstract}
Netrins are secreted molecules with roles in axonal growth and angiogenesis. The Netrin receptor UNC5B is required during embryonic development for vascular patterning, suggesting that it may also contribute to postnatal and pathological angiogenesis. Here we show that unc $5 b$ is down-regulated in quiescent adult vasculature, but re-expressed during sprouting angiogenesis in matrigel and tumor implants. Stimulation of UNC5B-expressing neovessels with an agonist (Netrin-1) inhibits sprouting angiogenesis. Genetic loss of function of unc $5 b$ reduces Netrin-1-mediated angiogenesis inhibition. Expression of UNC5B full-length receptor also triggers endothelial cell repulsion in response to Netrin-1 in vitro, whereas a truncated UNC5B lacking the intracellular signaling domain fails to induce repulsion. These data show that UNC5B activation inhibits sprouting angiogenesis, thus identifying UNC5B as a potential anti-angiogenic target.
\end{abstract}

[Keywords: Vessel guidance; axon guidance molecules; tip cell; neovascularization; tumor angiogenesis]

Supplemental material is available at http://www.genesdev.org.

Received April 23, 2007; revised version accepted August 3, 2007.

Blood vessels and nerves are complex branched networks that require guidance to ensure their proper positioning in the body. Recent studies have demonstrated that specialized endothelial cells, resembling axonal growth cones, are located at the tips of growing capillaries. These endothelial tip cells guide outgrowing capillaries in response to gradients of extracellular matrix-bound vascular endothelial growth factor (VEGF) (Gerhardt et al. 2003; Olsson et al. 2006; Shibuya 2006). Several families of axon guidance molecules, including Semaphorins, Slits, and Netrins have also been implicated in vessel pathfinding and network formation (Carmeliet and Tessier-Lavigne 2005; Eichmann et al. 2005).

Three members of the netrin gene family, netrin-1, netrin-3, and $\beta$-netrin/netrin- 4 , have been identified in

\footnotetext{
${ }^{10}$ These authors contributed equally to this work.

Present addresses: ${ }^{11}$ Beijing Union Medical College and Chinese Academy of Medical Sciences, 100730 Beijing, China; ${ }^{12}$ School of Life Science, Xiamen University, 361005 Xiamen, China.

${ }^{13}$ Corresponding author.

E-MAIL anne.eichmann@college-de-france.fr; FAX 33-1-44271691.

Article is online at http://www.genesdev.org/cgi/doi/10.1101/gad.437807.
}

mammals (Serafini et al. 1996; Van Raay et al. 1997; Wang et al. 1999; Koch et al. 2000; Yin et al. 2000). Netrins are bifunctional guidance cues, attracting some axons while repelling others (Dickson 2002). Netrin-1 is secreted from cells at the ventral midline of the central nervous system and attracts commissural axons toward the midline. Netrins can, however, also repel certain axons, including the trochlear motor axons in vertebrates (Colamarino and Tessier-Lavigne 1995). Attraction and repulsion are mediated via activation of receptors of the deleted in colorectal cancer (DCC) and uncoordinated 5 (UNC5) families, respectively. The DCC family consists of DCC and Neogenin (Chan et al. 1996; Keino-Masu et al. 1996), while the UNC5 family comprises four members, UNC5A to UNC5D (Leung-Hagesteijn et al. 1992; Ackerman et al. 1997; Leonardo et al. 1997). Axon attraction is mediated by the DCC receptors (Fazeli et al. 1997), while repulsion requires signaling through UNC5-DCC receptor heterodimers or UNC5 receptor homodimers (Hedgecock et al. 1990; Hong et al. 1999; Keleman and Dickson 2001).

In addition to their role in axon guidance, Netrins and their receptors have been implicated in other develop- 
mental processes including angiogenesis (Cirulli and Yebra 2007). Netrins may also act as bifunctional cues during angiogenesis. Wilson et al. (2006) have shown promitogenic and promigratory effects with Netrin-1 and Netrin-4 in vitro and proangiogenic effects for both $\mathrm{Ne}$ trins in post-ischemic revascularization processes via unidentified receptor(s). In contrast, we have previously observed repulsive actions of Netrin-1 via UNC5B in developmental angiogenesis (Lu et al. 2004). We here examine for the first time expression of UNC5B and its function during postnatal and pathological angiogenesis, and show that activation of UNC5B with Netrin-1 as an agonist inhibits angiogenic sprouting and neovascularization.

\section{Results}

\section{Unc5b expression during postnatal and pathological angiogenesis}

To investigate possible functions of UNC5B during postnatal and/or pathological angiogenesis, we first examined its expression at different stages after birth, using heterozygous unc5b lacZ-plap knock-in mice bred onto a CD1 background (Lu et al. 2004). Whole-mount X-gal or alkaline phosphatase (AP) staining allows detecting both reporter genes inserted into the unc5b locus (Fig. 1; Supplementary Fig. 1). Staining of brains, hearts, guts, and skeletal muscle isolated from adult mice $(2-8 \mathrm{mo})$ showed no vascular staining in any of these organs (data not shown), indicating that unc5b expression is downregulated in the quiescent vasculature. To determine when unc5b down-regulation occurred, we examined retinal development, which is a temporally well-characterized, active sprouting angiogenesis process that starts at postnatal day 0 (P0) (Gariano and Gardner 2005). $U n c 5 b$ reporter gene expression was seen in arteries, capillaries, and endothelial tip cells of retinal vessels during the period of active angiogenesis (P0 until P8-P9) (Supplementary Fig. 1) and became progressively downregulated once angiogenesis of these vessels ceased. At P12, expression was observed in arteries, but extinguished in most capillaries (Fig. 1A-D). After P21, reporter staining in retinal vessels became undetectable (data not shown), and quantitative PCR (qPCR) analysis confirmed very low unc $5 b$ expression levels in adult retinal endothelial cells (Supplementary Fig. 1). Unc5b ex-

Figure 1. Unc5b expression during postnatal and pathological neovascularization. $(A-D)$ Unc5b plap $(A, C)$ reporter expression in the retina of $\mathrm{P} 12$ heterozygous mice double-stained with IsolectinB $_{4}$ $(B, D)$. $C$ and $D$ are higher magnifications of boxed areas in $A$ and $B$, respectively. $(C, D)$ Unc5b is expressed in arteries $(a)$, but most IsolectinB ${ }_{4}$-labeled capillaries are negative. $(E-H)$ Unc5b plap $(E, G)$ reporter expression in the OIR retina of P17 mice double-stained with IsolectinB 4 $(F, H)$. $G$ and $H$ are higher magnifications of boxed areas in $E$ and $F$, respectively. $(G, H)$ $U n c 5 b$ is up-regulated in arteries and sprouting vessels. $\left({ }^{*}\right)$ Arterio-venous shunt; (v) vein. (I) Whole-mount X-gal staining of skin of an adult heterozygous unc5b-LacZ-plap mouse shows weak unc $5 b$ expression in arteries (a) but not in veins $(\mathrm{v})$, and expression in hair follicles (arrowheads). $(J, K)$ bFGF-containing matrigel plug injected into a heterozygous unc5b-LacZ-plap mouse. Whole-mount Xgal staining $(J)$ of the freshly dissected plug $(K)$ shows up-regulation of unc5b expression in vessel sprouts (arrowheads) and arteries (a) but not veins (v). ( $L$ ) Section of a matrigel plug stained with X-gal and PECAM-1. Note unc5b expression in endothelial cells (arrowheads) and a smooth muscle cell $\left(^{\star}\right)$. $(M-P)$ PC3 tumor cells implanted for $7 \mathrm{~d}$ into a heterozygous unc $5 b$ LacZ-plap mouse. Whole-mount AP $(M)$
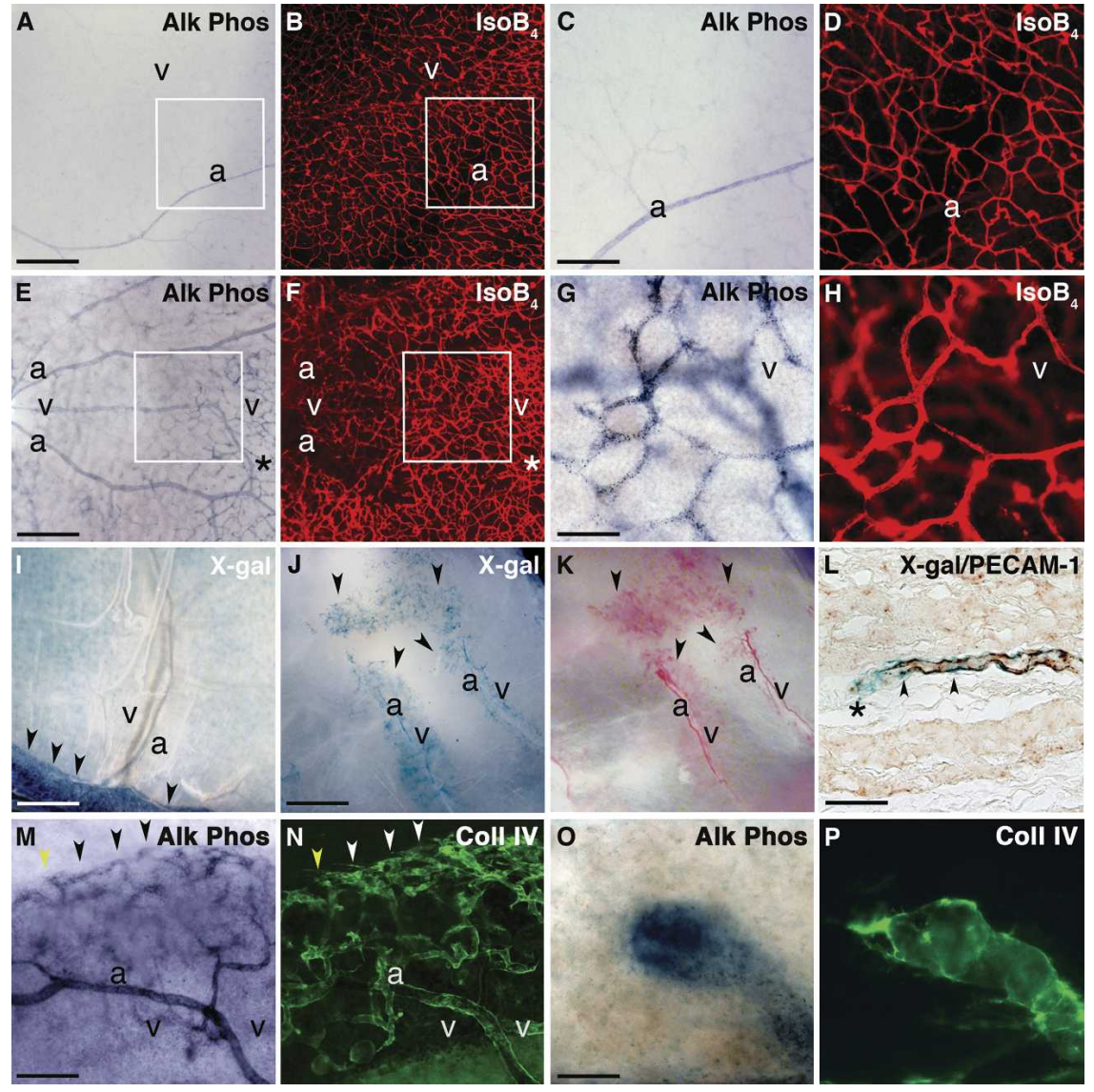

collagen-IV $(N)$ double staining of a thick section of a tumor nodule. Note unc $5 b$ expression in tumor arteries $(\mathrm{a})$, but not veins $(\mathrm{v})$, and in sprouting capillaries (arrowheads). $(O, P)$ Higher magnification of a sprout (yellow arrowhead in $M$ and $N)$ expressing the unc $5 b$ lac- $Z$ reporter $(O)$ and double-stained with Collagen-IV $(P)$. Bars: $A, B, E, F, 225 \mu \mathrm{m} ; C, D, L-N, 110 \mu \mathrm{m} ; G, H, 45 \mu \mathrm{m} ; I, 1500 \mu \mathrm{m} ; J, K, 2000 \mu \mathrm{m}$; $O, P, 25 \mu \mathrm{m}$. 
pression thus appears restricted to vessels undergoing active angiogenesis and becomes down-regulated once these vessels reach quiescence.

To test if induction of neovascularization was accompanied by re-expression of unc $5 b$, we subjected mice to oxygen-induced ischemic retinopathy (OIR) (Smith et al. 1994). Briefly, mice were exposed to hyperoxia between $\mathrm{P} 7$ and P12, followed by return to room air until P17. The return to room air is perceived as a hypoxic insult, leading to VEGF up-regulation and reactivation of angiogenic sprouting. Unc5b was robustly re-expressed in arteries, in arterio-venous shunts, and in sprouting capillaries at P17 (Fig. 1E-H).

To extend these observations, we injected matrigel loaded with the proangiogenic factor bFGF into heterozygous unc5b lacZ-plap knock-in mice to induce sprouting and invasion of subcutaneous vessels into the plug (Kleinman and Martin 2005). Whole-mount X-gal staining of adult skin showed weak unc5b expression in arteries, while neovessels invading the plugs up-regulated unc $5 b$ transcription 2 wk post-injection. Re-expression was observed in arteries, but not in veins, and in sprouting vessels (Fig. 1I-K). Double staining with the panvascular marker PECAM-1 showed that re-expression occurred in endothelial cells and, to a lesser extent, in smooth muscle cells (Fig. 1L). Results obtained in the unc5b lacZ-plap reporter mice were confirmed in C57/ B16 mice using in situ hybridization with a probe recognizing unc5b (Supplementary Fig. 2).

To determine if unc $5 b$ expression was also up-regulated during tumor angiogenesis, PC3 prostate cancer cells were implanted subcutaneously into unc5b lacZplap knock-in mice, harvested after $1 \mathrm{wk}$ and analyzed for unc5b AP reporter expression followed by labeling with an anti-Collagen-IV antibody that recognizes vascular basement membranes (Baluk et al. 2003). No signs of immune reaction could be detected at this time point, presumably due to low HLA surface expression (Benimetskaya et al. 2004). Robust unc5b expression was observed in vessels invading the tumors, most prominently in arteries, but not veins, and in sprouting capillary endothelium (Fig. 1M-P). Similar results were obtained using implantation of tumor cell lines in nude mice by in situ hybridization with an unc5b-specific probe (Supplementary Fig. 1).

Finally, we tested for unc5b re-expression following femoral artery ligation in $\mathrm{C} 57 / \mathrm{Bl6}$ and heterozygous unc5b lacZ-plap reporter mice. Paraffin sections of gastrocnemius muscle from either control or ligated limbs 7 and $14 \mathrm{~d}$ after femoral artery ligation were prepared. Lectin staining showed numerous enlarged vessels in the ischemic muscle, indicating that ligation had induced a vascular response (Supplementary Fig. 1). While in situ hybridization failed to detect unc5b up-regulation, X-gal staining revealed some positive cells in the mesenchyme of the ischemic area. Both stainings failed to detect $u n c 5 b$ up-regulation in endothelium of the ischemic vessels (Supplementary Fig. 1). Thus, during this form of neovascularization, which may not require extensive sprouting, endothelial unc5b expression is not induced.
Taken together, these data show that unc5b expression is dynamically regulated during postnatal life and correlated with sprouting angiogenesis in both physiological and pathological processes.

\section{Inhibition of matrigel neovascularization by Netrin-1 requires $U N C 5 B$}

As unc $5 b$ expression accompanied bFGF-induced matrigel neovascularization (Fig. 1I-L; Supplementary Fig. 2), we examined the effects of UNC5B activation by Netrin-1 in this model. Matrigel plugs loaded with saline (control), recombinant Netrin-1 (300 ng/mL or $1 \mu \mathrm{g} / \mathrm{mL}$ ), bFGF $(300 \mathrm{ng} / \mathrm{mL})$, or bFGF in combination with Netrin-1 were injected into C57/B16 or heterozygous unc5bLacZ-plap mice and analyzed after $14 \mathrm{~d}$. Angiogenesis in the C57/B16 matrigel plugs was assayed by measurement of hemoglobin content, VEGF Receptor-2 (VEGFR-2) protein concentration, assessment of vessel morphology after perfusion of fluorescently labeled IsolectinB $\mathrm{B}_{4}$, and PECAM-1 staining of sections prepared from matrigel plugs (Fig. 2A-D; Supplementary Fig. 2). Neovascularization in heterozygous unc5b lacZ-plap mice was assayed by whole-mount X-gal staining and counting of the number of X-gal-positive blood vessels on serial paraffin sections prepared from matrigel plugs (Fig. 2E-J). Plugs containing saline or Netrin-1 alone exhibited no significant invasion of unc5b-expressing blood vessels (Fig. 2A,B,E,H). Thus, Netrin-1 showed no angiogenic activity in this assay. As expected, bFGF robustly stimulated neovascularization and invasion of unc $5 b$-expressing vessels. In comparison with bFGF alone, vascularization of plugs containing bFGF and Netrin-1 was significantly reduced (Fig. 2A-J; Supplementary Fig. 2). Higher magnifications of X-gal whole-mount stainings showed numerous unc $5 b$-positive sprouts at the vascular front protruding into the matrigel in bFGF-containing plugs, while protrusion of sprouts was reduced in plugs containing both bFGF and Netrin-1 (Fig. 2I,J).

Expression of all known Netrin receptors was examined in bFGF-treated matrigel plugs by RT-PCR. Only unc $5 b$ and, at lower levels, unc5 $a$ and neogenin could be amplified (Supplementary Fig. 2), suggesting that inhibition of bFGF-induced neovascularization by Netrin-1 could be at least partly mediated by the UNC5B receptor. To test this hypothesis directly, we used adult homozygous unc5b-deficient mice. Our previous analysis of an unc5b knock-out mouse had shown that the homozygous mutants die in midgestation (Lu et al. 2004). However, mating of a large number (>100 females) of heterozygous CD1-unc5b lacZ-plap mice revealed that a small fraction of newborn offspring $(\sim 4.5 \%)$ was homozygous for the unc5b mutation, and we were able to derive viable mice from those offspring. Adult skin vasculature was morphologically similar in $u n c 5 b^{+/-}$and $u n c 5 b^{-/-}$ mice, consistent with the absence of unc $5 b$ expression in adult skin vessels. Homozygous and heterozygous unc $5 b$ mice were injected with matrigel containing bFGF on one flank and bFGF plus Netrin-1 (300 ng/mL) on the other flank. Whole-mount X-gal staining showed similar 
Figure 2. Inhibition of matrigel neovascularization by Netrin-1. $(A-D)$ Matrigel plugs in C57/B16 wild-type mice $(+/+)$. $(A, B)$ Quantification of hemoglobin content $(A)$ and VEGFR-2 protein levels $(B)$. bFGF is at $300 \mathrm{ng} / \mathrm{mL}$, and Netrin-1 (Net) is at 300 or $1000 \mathrm{ng} / \mathrm{mL} . n=10$ mice per growth factor treatment; two independent groups of mice for $A$ and $B .(C, D)$ Vessel morphology in matrigel plugs containing bFGF $(C)$ or bFGF and Netrin-1 (both at $300 \mathrm{ng} / \mathrm{mL})(D)$ after IsolectinB ${ }_{4}$ perfusion. $(D)$ Note reduction of vessel branching in the presence of Netrin-1. $(E-G)$ Wholemount X-gal staining of matrigel plugs in unc $5 b^{+/-}$mice. Note little invasion of unc $5 b$-expressing vessels (dashed areas) in plugs containing Netrin-1 alone $(E)$, robust stimulation of neovascularization by bFGF $(F)$, and inhibition of neovascularization in plugs containing both factors at $300 \mathrm{ng} / \mathrm{mL}(G)$. (H) Quantification of serial paraffin sections prepared from matrigel plugs. The number of sections invaded by at least one blood vessel was scored on 100-200 sections per plug. $n=1$ control, 3 unc $5 b^{+/-}$mice treated with $1000 \mathrm{ng} / \mathrm{mL}$ Netrin-1, 4 unc $5 b^{+/-}$and 5 unc $5 b^{-1-}$ mice treated with bFGF and with bFGF and $\mathrm{Ne}$ trin-1. $(I, J)$ Higher magnification of vascular front (corresponding to boxed areas in $F$ and $G$, respectively). Note numerous sprouts extending into the gel in the presence of bFGF alone ( $I$, arrowheads), while less sprouts are observed in the presence of both bFGF and Netrin-1 $(300 \mathrm{ng} / \mathrm{mL})(J$, arrowhead). $(K, L)$ Overview of X-gal-stained plugs in unc $5 b^{-/-}$mice. Note similar vascularization (dashed areas) in absence $(K)$ and presence $(L)$ of Netrin-1. $(M, N)$ Vascular front (corresponding to boxed areas in $K$ and $L$, respectively) in matrigel plugs injected into unc $5 b^{-/-}$mice. Note similar numbers of sprouts in the absence $(M)$ and presence $(N)$ of Netrin-1. Bars: $C, D, 75 \mu \mathrm{m}, E-G, K, L, 233 \mu \mathrm{m} ; I, J, M, N, 26 \mu \mathrm{m}$.

vascularization in bFGF-containing plugs implanted into unc $5 b^{+/-}$and unc $5 b^{-/-}$mice. However, the inhibition of blood vessel invasion by Netrin-1 observed in $u n c 5 b^{+/-}$ mice was reduced in unc $5 b^{-/-}$mutants (Fig. $2 \mathrm{H}, \mathrm{K}-\mathrm{N}$ ). Angiogenic sprouting into the matrigel in unc $5 b^{-/-} \mathrm{mu}-$ tants was similar in plugs containing bFGF alone or bFGF combined with Netrin-1 and strongly contrasted with blunted sprout extension in plugs containing bFGF and Netrin-1 observed in heterozygotes (Fig. 2I,J,M,N). Counting of the number of sections invaded by unc $5 b$ positive blood vessels confirmed a significant decrease in unc $5 b^{+/-}$, but not in unc $5 b^{-1-}$ mice, in the presence of Netrin-1 (Fig. 2H). Taken together, these results show that Netrin-1 inhibits neovessel sprouting via UNC5B.

\section{Tip cell filopodial retraction in response to Netrin-1 requires $U N C 5 B$}

To understand how Netrin-1 could inhibit vessel sprouting, we used an ex vivo endothelial sprouting assay. Dorsal aorta explants from wild-type, $u n c 5 b^{+/-}$and unc $5 b^{-/-}$mice were cultured in semisolid collagen gels. After $48 \mathrm{~h}$, the explants developed sprouts that extended peripherally and were spearheaded by filopodial-extending cells. Whole-mount staining of $u n c 5 b^{+/-}$and unc $5 b^{-1-}$ explants using $\mathrm{X}$-gal showed that sprouting cells expressed unc5b (Fig. 3A,B). Paraffin sections of explants double-labeled with X-gal and PECAM-1 showed lumenized PECAM-1/X-gal-positive vessels close to the center of the explants (Fig. 3C). Peripheral $\mathrm{X}$-gal-positive filopodia-extending cells also stained with PECAM-1 (Fig. 3D), indicating that they were endothelial cells.

We then subjected individual endothelial tip cells to gradients of recombinant Netrin-1. The tip cell response was recorded by time-lapse videomicroscopy over $2 \mathrm{~h}$ and filopodial length was measured at the beginning and the end of the experiment (Fig. 3E-I). Injection of Netrin-1 induced filopodial retraction in $u n c 5 b^{+/+}$and unc $5 b^{+/-}$tip cells (Fig. 3E-G; Supplementary Movie 1). In contrast, unc $5 b^{-/-}$tip cells showed filopodial movement, but no significant filopodial retraction in response to $\mathrm{Ne}$ trin-1 (Fig. 3E,H,I; Supplementary Movie 2). Importantly, the absence of UNC5B did not result in a conversion of the repulsive response to an attractive one; i.e., an increase in filopodial length. Thus, Netrin-1 induces filo- 


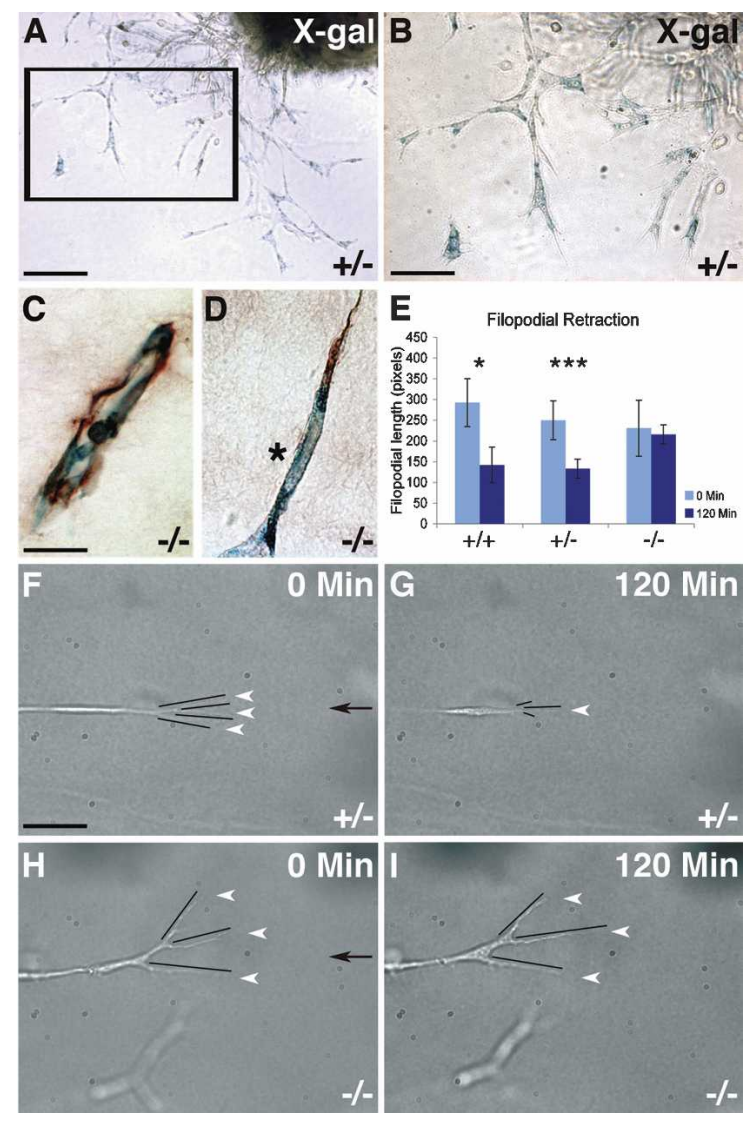

Figure 3. Unc5b-expressing endothelial tip cells retract filopodia in response to Netrin-1 aortic ring assays. $(A, B)$ Sprouts growing from heterozygous unc5b lacZ-plap aortic rings into collagen gels stain with X-gal. $B$ is a higher magnification of boxed area in $A$. $(C, D) \mathrm{X}$-gal/PECAM-1 double staining of sections prepared from explants show lumenized vessels close to the explant $(C)$ and double-staining of tip cells $(D) .\left(^{*}\right)$ Tip cell nucleus. $(E-I)$ Tip cell response to gradients of recombinant Netrin-1 recorded by time-lapse videomicroscopy. $(E)$ Quantification of filopodial length at the beginning $(t=0)$ and the end of the time-lapse movies $(t=120 \mathrm{~min}) .(F-I)$ Responses of individual tip cells from unc $5 b^{+/-}(F, G)$ and unc $5 b^{-/-}(H, I)$ explants to gradients of recombinant Netrin-1 (gradient source indicated by black arrows in $F$ and $H$ ). Still images from time-lapse movies at the indicated time points. White arrowheads point to filopodia. Filopodial length is indicated by black lines. Note filopodial retraction in $G$, but not in $I$. Total number of tip cells analyzed: six $+/+, 17+/-$, and $16-/-$. Error bars, SEM; $\left({ }^{\star}\right) P<0.05$; $\left.{ }^{\star \star \star}\right)$ $P<0.001$, Mann-Whitney $U$-test. Bars: $A, 170 \mu \mathrm{m} ; B, 85 \mu \mathrm{m}$; $C, D, 20 \mu \mathrm{m} ; F-I, 45 \mu \mathrm{m}$.

podial retraction of endothelial tip cells via the UNC5B receptor, providing a rational mechanism to account for the observed inhibitory effects during matrigel neovascularization.

\section{UNC5B signaling mediates endothelial repulsion in response to Netrin-1}

We asked if signaling from the UNC5B intracellular domain was required to transduce the response to Netrin-1 in endothelial cells in vitro. Porcine aortic endothelial cells (PAECs) were stably transfected with a construct encoding full-length $(\mathrm{FL})$ rat UNC5B fused to a C-terminal GFP-tag (UNC5B FL) or with a construct containing a deletion of the entire UNC5B cytoplasmic domain fused to GFP (UNC5B $\triangle C D$ ). Immunoblot analysis from PAEC lysates using anti-GFP and anti-UNC5B antibodies showed a single band of the expected size in each cell line, with expression levels of the UNC5B $\triangle C D$ clone being higher than for UNC5B FL (Supplementary Fig. 3).

To test for Netrin-1 effects on sprouting of UNC5Bexpressing cells, UNC5B FL, $\triangle \mathrm{CD}$, or parental PAECs were seeded onto microcarrier beads and embedded in fibrin gels with or without recombinant Netrin-1. Sprouting of UNC5B $\triangle$ CD cells or parental PAECS was similar in the presence or absence of Netrin-1, whereas sprouting of UNC5B FL cells was significantly reduced in the presence of Netrin-1 (Fig. 4A-E). Thus, expression of UNC5B was sufficient to mediate inhibition of endothelial sprouting in response to Netrin-1 in vitro, and sprouting inhibition required the presence of the UNC5B intracellular signaling domain.

To test for possible effects of Netrin-1 on PAEC proliferation, parental, UNC5B FL, and UNC5B $\triangle$ CD cells were cultured in low serum and stimulated with either fetal bovine serum (FBS) or different concentrations of recombinant Netrin-1. While robust proliferation was observed in response to serum, no proliferation was induced in the presence of Netrin-1 (Supplementary Fig. 3). The effects of Netrin-1 on UNC5B-expressing endothelial cells thus involve sprouting rather than proliferation. In contrast to previous reports (Wilson et al. 2006), recombinant Netrin-1 also had no significant effects on HUVEC or HUAEC proliferation, while VEGF robustly stimulated proliferation of both cell types (Supplementary Fig. 3).

To examine if Netrin-1 induced changes in UNC5B receptor localization, subconfluent UNC5B FL and $\triangle \mathrm{CD}$ PAECs in two-dimensional cultures were treated with recombinant Netrin-1 and observed by fluorescence microscopy. Control or BSA-treated UNC5B FL and $\triangle \mathrm{CD}$ PAECs showed membrane fluorescence that was particularly strong at cell-cell junctions (Fig. 4F,I). By 15 min after addition of Netrin-1 at 100 or $500 \mathrm{ng} / \mathrm{mL}$, UNC5B FL PAECs aggregated GFP-tagged receptor at filopodial cytoplasmic extensions, accompanied by formation of gaps between cells, suggestive of cytoskeletal retraction (Fig. 4F-H). Similar results were obtained with DsRed-tagged UNC5B FL PAECs (data not shown). The response was specific for Netrin-1 and was not observed after addition of other growth factors, including Netrin-4 (data not shown), which has been reported not to bind UNC5B (Wilson et al. 2006). UNC5B $\Delta$ CD-expressing cells did not show receptor aggregations or retraction at any Netrin-1 dose tested (Fig. 4J,K). Time-lapse videomicroscopy of the cells confirmed that UNC5B FL, but not $\triangle \mathrm{CD}$ constructs, respond to Netrin-1 by retraction (Supplementary Movies 3, 4). Thus, Netrin-1-UNC5B signaling triggers endothelial cell retraction in vitro. 
Figure 4. Repulsion of PAECs expressing FL UNC5B in the presence of Netrin-1. $(A-E)$ Gelatin-coated microcarrier beads were seeded with parental, UNC5B FL, or UNC5B $\triangle$ CD (UNC5B CD) PAECs and embedded in fibrin gels supplemented with $10 \%$ FBS or $10 \%$ FBS and $300 \mathrm{ng} /$ $\mathrm{mL}$ Netrin-1. (E) Endothelial sprout formation was quantified after $24 \mathrm{~h}$ (cumulative sprout length per bead). $n=4$ (UNC5B FL) or 3 (parental and UNC5B CD) experiments performed in triplicate. Error bars: SEM; $\left(^{\star \star}\right) P<0.025$, MannWhitney $U$-test. $(F-H)$ Confocal images of UNC5B FL PAECs treated with BSA $(F)$ or with recombinant mouse Netrin-1 at $100 \mathrm{ng} / \mathrm{mL}(G)$ or $500 \mathrm{ng} / \mathrm{mL}(H)$ for $30 \mathrm{~min}$. Note dose-dependent receptor aggregation at filopodial extensions (arrowheads) and cell retraction $\left({ }^{\star}\right) .(I-K)$ UNC5B CD PAECs treated with BSA $(I)$ or with recombinant mouse Netrin-1 $(J, K)$. Note absence of retraction. Bars: $A-D, 115 \mu \mathrm{m} ; F-K, 30 \mu \mathrm{m}$.
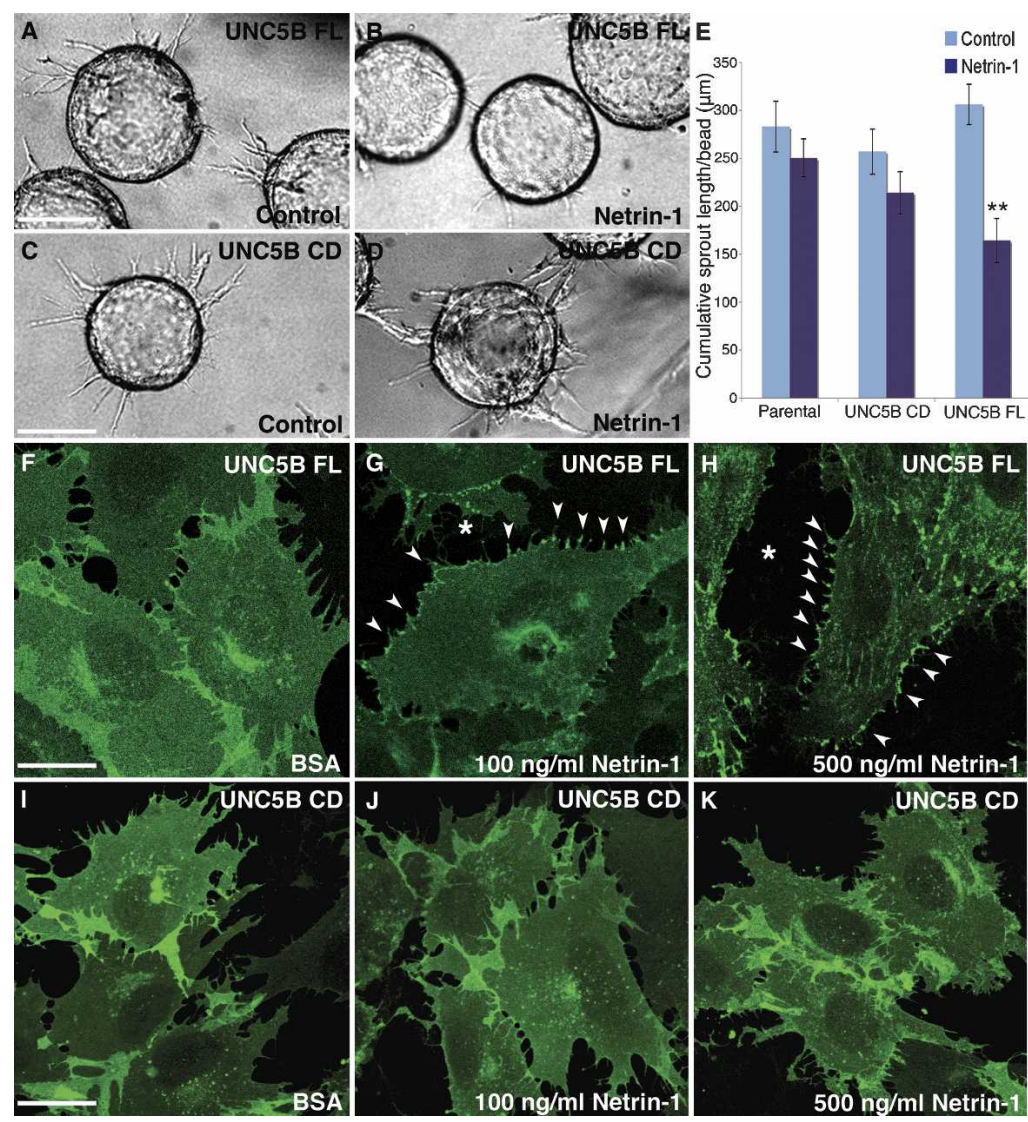

Netrin-1 expression in tumor cells repels UNC5B-expressing endothelial cells

To determine if Netrin-1/UNC5B signaling could have a role in tumor angiogenesis, we first examined Netrin-1 expression in tumor cells. We screened 20 different human tumor cell lines of diverse origin for expression of netrins and their receptors by semiquantitative RT-PCR (Fig. 5). Most cell lines expressed netrin-4, but showed no or little expression of netrin-1 or netrin-3. Netrin receptors were also heterogeneously expressed by the tumor cell lines: neogenin was detected in most cell lines, $d c c$ was detected in only one cell line, and expression of the unc5 receptors varied greatly between different lines (Fig. 5).

The low or undetectable levels of the UNC5B ligands netrin-1 and netrin-3 (Leonardo et al. 1997; Wang et al. 1999) were consistent with the absence of inhibitors and thus invasive sprouting of blood vessels into tumors derived from these cells. To test this idea, we examined effects of tumoral Netrin-1 overexpression on the behavior of UNC5B-expressing endothelial cells. Three cell lines were selected for expressing Netrin-1: Miapaca pancreatic cancer cells and Mel2a melanoma cells, which did not express any endogenous netrins, and PC3 prostate carcinoma cells, which expressed netrin-4. We overexpressed human Netrin-1 in these cells using retroviral gene transfer. Western blot analysis with anti-His antibody recognizing an $\mathrm{N}$-terminal tag (data not shown) or anti-mouse Netrin-1 antibodies, which recognize human Netrin-1, showed that Netrin-1-transduced cells secreted Netrin-1 protein into the medium (Supplementary Fig. 4). The levels of Netrin-1 in cell supernatants were confirmed by solid phase receptor assay with plates coated with an UNC5B-Fc chimera (Miapaca: $148 \pm 51$ $\mathrm{ng} / \mathrm{mL}$; Mel2a: $98 \pm 20 \mathrm{ng} / \mathrm{mL}$; PC3: $19 \pm 9 \mathrm{ng} / \mathrm{mL}$ ) and were consistent with the immunoblotting results. Semiquantitative RT-PCR showed that except for netrin-1, the expression of other netrins and their receptors was similar between Netrin-1-transduced and empty-vectortransduced or parental cells (Fig. 5; data not shown). Proliferation, apoptosis, and clone-forming ability in soft agar of empty vector- and Netrin-1-transduced cells were comparable (Supplementary Fig. 4). Thus, retroviral Netrin-1 overexpression had no obvious effect on tumor cell behavior in vitro.

We then tested the response of UNC5B-expressing endothelial cells to Netrin-1 secreted from transduced tumor cells in vitro. Control or Netrin-1-expressing tumor cells were added to UNC5B FL or $\triangle$ CD PAECs and the PAEC response was recorded over a period of $24 \mathrm{~h}$. Immunostaining of cocultures with a Netrin-1 antibody showed that Netrin-1-producing, but not control-infected tumor cells exhibited Netrin-1 immunofluorescence (Supplementary Fig. 3). Netrin-1 immunoreactivity was also observed at the surface of UNC5B FL- and $\triangle \mathrm{CD}$-expressing PAECs adjacent to Netrin-1-producing 


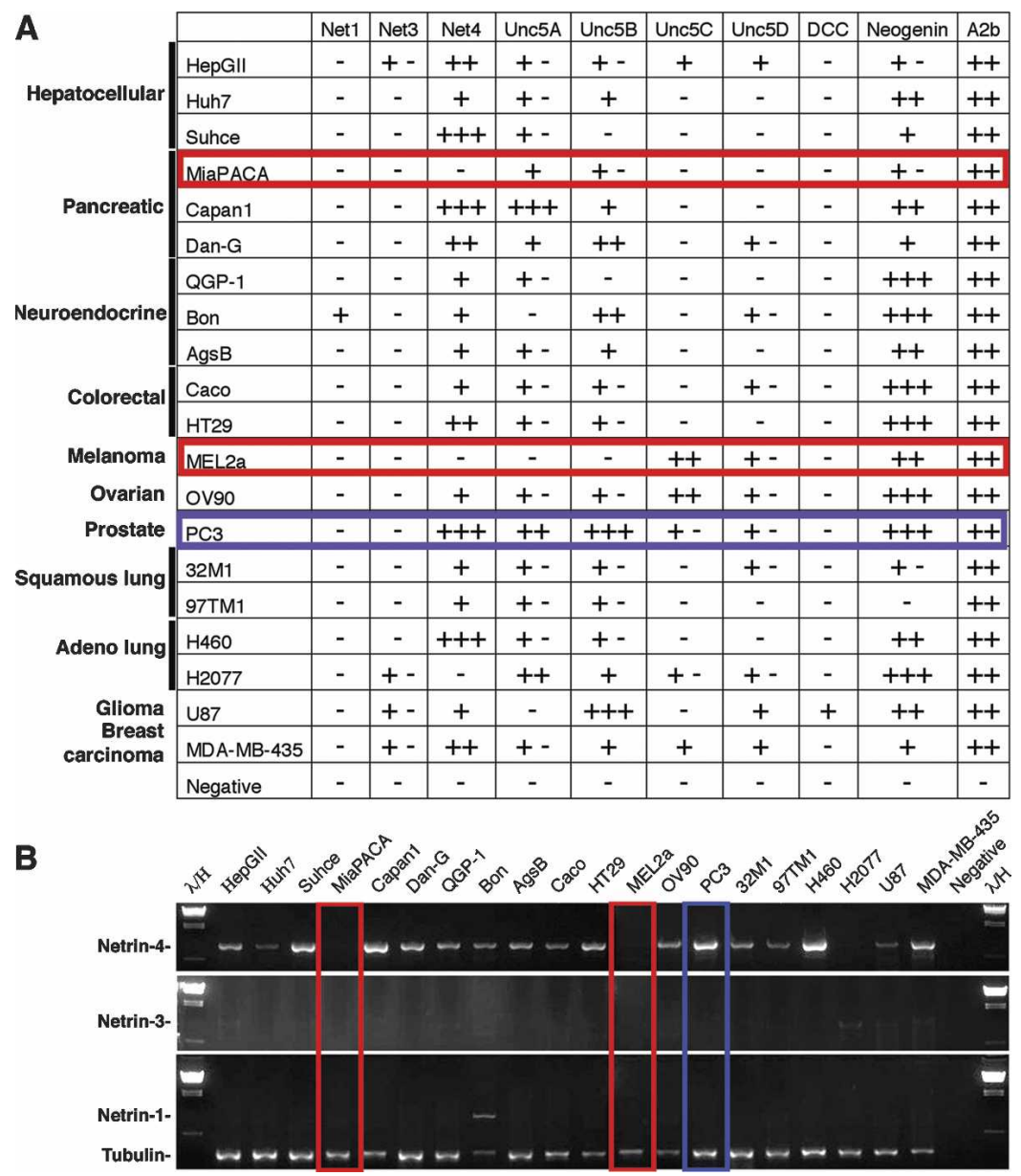

Figure 5. Expression of netrins and their receptors in human tumor cell lines. (A) Three-hundred nanograms of total RNA extracted from the indicated tumor cell lines were reverse-transcribed with oligo-dT and amplified with primer pairs specific for the indicated genes and tubulin. Two independent RT and PCR reactions (32 and 40 cycles, respectively) were performed, with similar results. (-) No amplification; (+-) weak or no amplification at 32 cycles, but band detectable after 40 cycles; $(+)$ band present in both amplifications; $(++)$ strong band; $(+++)$ very strong band. (B) Gels representing 40 cycle amplifications of netrin-1, netrin-3 and netrin-4. Note absence of netrin expression in Miapaca pancreatic cancer cells and Mel2a melanoma cells (outlined in red) and presence of netrin-4 in PC3 prostate cancer cells (outlined in blue). tumor cells, presumably indicating ligand binding to receptor. Brightest Netrin-1 immunofluorescence was seen on cytoplasmic GFP-positive extensions formed by UNC5B FL cells next to Netrin-1-producing tumor cells (Supplementary Fig. 3). Videomicroscopy showed that by 15 min after addition of Netrin-1-expressing tumor cells, UNC5B FL PAECs adjacent to the added tumor cells aggregated GFP-tagged receptor and retracted their cytoskeleton (data not shown). After 6 and 24 h, Netrin-1producing tumor cells were spatially segregated from UNC5B FL cells, consistent with a repulsive effect of the tumor cells on endothelial cells expressing UNC5B (Fig. 6D-F). UNC5B-GFP aggregation or retraction of UNC5B FL PAECs was not observed with control-infected tumor cells, and the two cell populations were mixed after $24 \mathrm{~h}$ (Fig. 6A-C). Tumor cells expressing Netrin-1 did not induce retraction of UNC5B $\triangle$ CD-expressing PAECs, and the two cell populations were again mixed after $24 \mathrm{~h}$ (Fig. 6G-I). Quantification of the overlap between tumor cells and PAECs showed a significant reduction in cocultures of UNC5B FL PAECs with Netrin-1-secreting tumor cells (Fig. 6J). Thus, Netrin-1 secreted by all three transduced tumor cell lines triggers endothelial cell repulsion after binding to UNC5B.
Netrin-1 reduces sprouting of unc5b-positive vessels and delays tumor angiogenesis

The effects of Netrin-1 overexpression on tumor angiogenesis were tested by subcutaneous xenografts of transduced Mel2a, Miapaca, and PC3 tumor cells into nude mice. Tumors were harvested at different time points post-implantation ( $n=3$ per group per time point) and examined for vascularization using unc $5 b$ in situ hybridization and PECAM-1 staining. In control tumors, unc5b expression was prominent in sprouting vessels (Fig. 7B,H; Supplementary Fig. 5). Unc5b expression was also observed around Netrin-1-overexpressing tumors (Fig. 7D; Supplementary Fig. 5). However, these vessels remained localized at the tumor periphery, avoiding Netrin-1-expressing tumor areas. Quantification showed a significant reduction of the number of unc5b-positive vessels as well as overall vessel number in Netrin-1overexpressing compared with control tumors 1 and 2 wk post-implantation (Fig. 7E,K). At later stages postimplantation, the number of unc5b-expressing vessels remained significantly lower in Netrin-1-overexpressing compared with control tumors at all time points and in all tumors analyzed (Fig. 7E,K; Supplementary Fig. 5). 
Figure 6. Repulsion of UNC5B FL PAECs by Netrin1 -overexpressing tumor cells. $(A-C)$ Confocal images from cocultures of PAECs expressing UNC5B FL (green) with the indicated control-infected tumor cell lines labeled with the lipophilic fluorescent dye PKH26 (red). Note mixing of the two populations after $24 \mathrm{~h}$ of culture. $(D-F)$ PAEC UNC5B FL cells cocultured with the indicated Netrin-1-transduced tumor cell lines. Note formation of UNC5B GFP aggregations (arrowheads) next to Netrin-1-producing tumor cells and segregation of PAECs from tumor cells. $(G-I)$ UNC5B $\triangle C D$ PAECs do not segregate from Netrin-1-secreting tumor cells. (J) Quantification of the overlap of tumor cells by endothelial cells. The area of PAECs covered by tumor cells was measured on six images per well in three independent experiments. Error bars: SEM; $\left(^{\star}\right) P<0.05$, MannWhitney $U$-test. Bars, $80 \mu \mathrm{m}$.
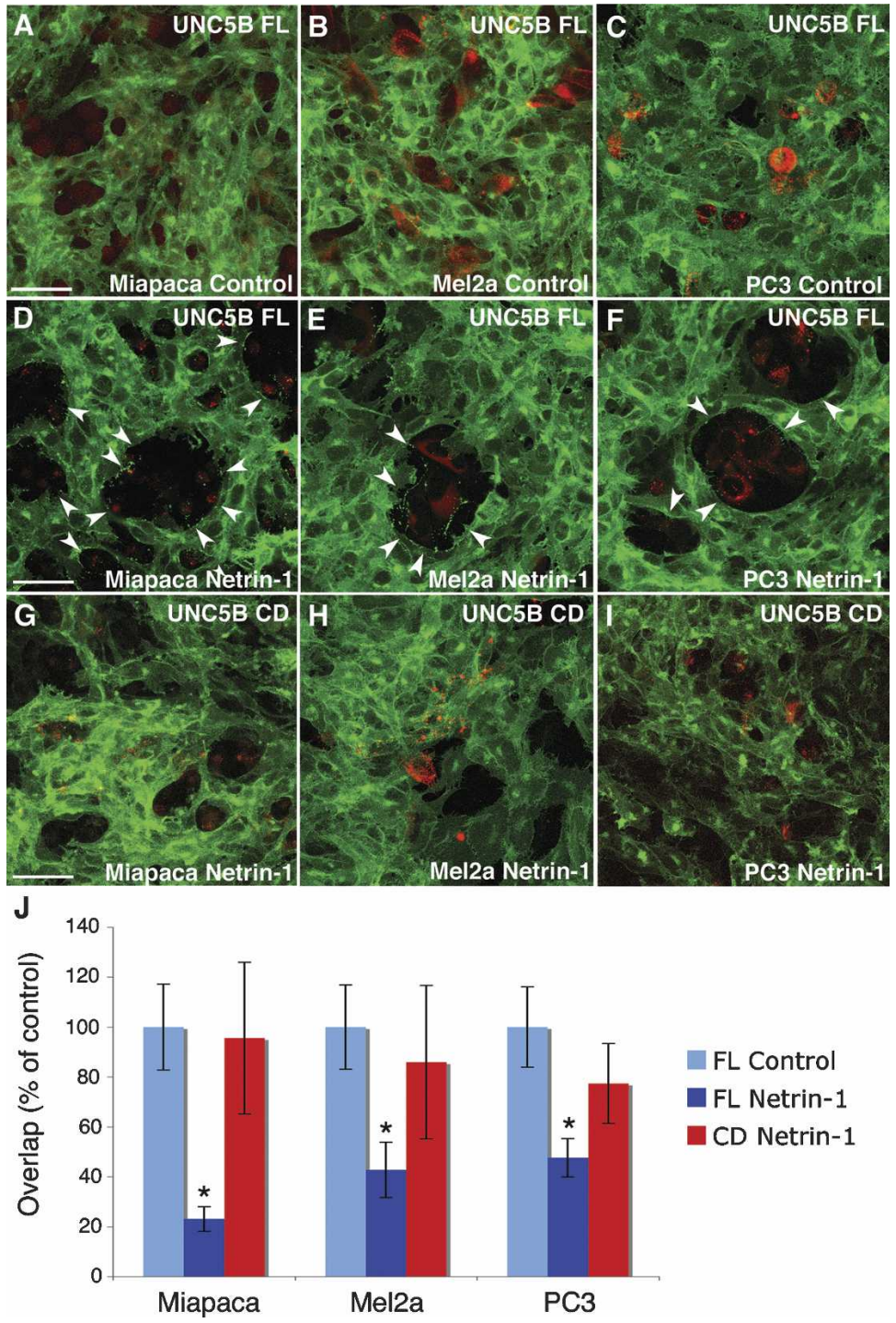

However, blood vessel density in Netrin-1-overexpressing tumors progressively increased and reached levels comparable with control-infected tumors. Thus, compared with controls, Netrin-1 overexpression delayed tumor vascularization, and this delay was correlated with the inhibition of sprouting of unc $5 b$-expressing vessels during the initial stages of neovascularization.

Consequently, overexpression of Netrin-1 had mainly inhibitory effects on tumor growth: It greatly inhibited the growth of Mel2a tumors and delayed the growth of PC3 tumors (Fig. 7F; Supplementary Fig. 5). While Netrin-1 overexpression did not significantly affect the growth of Miapaca tumors (Fig. 7L), histological analysis of these tumors at $6 \mathrm{wk}$ post-implantation showed necrotic tumor areas and a reduction of overall tumor angiogenesis (Fig. 7K; Supplementary Fig. 6). Phospho-histoneH3 staining to label proliferating tumor and endothelial cells in all tumor types at $6 \mathrm{wk}$ post-implantation showed no difference in cell proliferation between Netrin-1-overexpressing tumors and controls /data not shown). CD45 staining revealed no difference in leukocyte invasion (data not shown). The effects of Netrin-1 overexpression on tumor angiogenesis and growth are thus likely a consequence of the initial inhibition of sprouting of unc $5 b$-expressing vessels.

We finally tested if UNC5B mediated the inhibitory effects of Netrin-1 overexpression on tumor angiogenesis. Heterozygous and homozygous unc5b lacZ-plap knock-in mice received on each flank subcutaneous xenografts of PC3 tumor cells transduced with either control-vector or Netrin-1. Whole-mount collagen-IV staining of PC3 tumors was performed after 1 wk. Low magnification images of tumors implanted in heterozygous mice showed a significant reduction of the vascularized area in the Netrin-1-transduced compared with control tumors (Fig. 8A,B,D). Higher magnification images revealed active sprouting of skin vessels into control vector tumors (Fig. 8E,F) that was inhibited in Netrin-1expressing tumors, resulting in a blunted appearance of vessels sprouts very similar to that observed in the ma- 

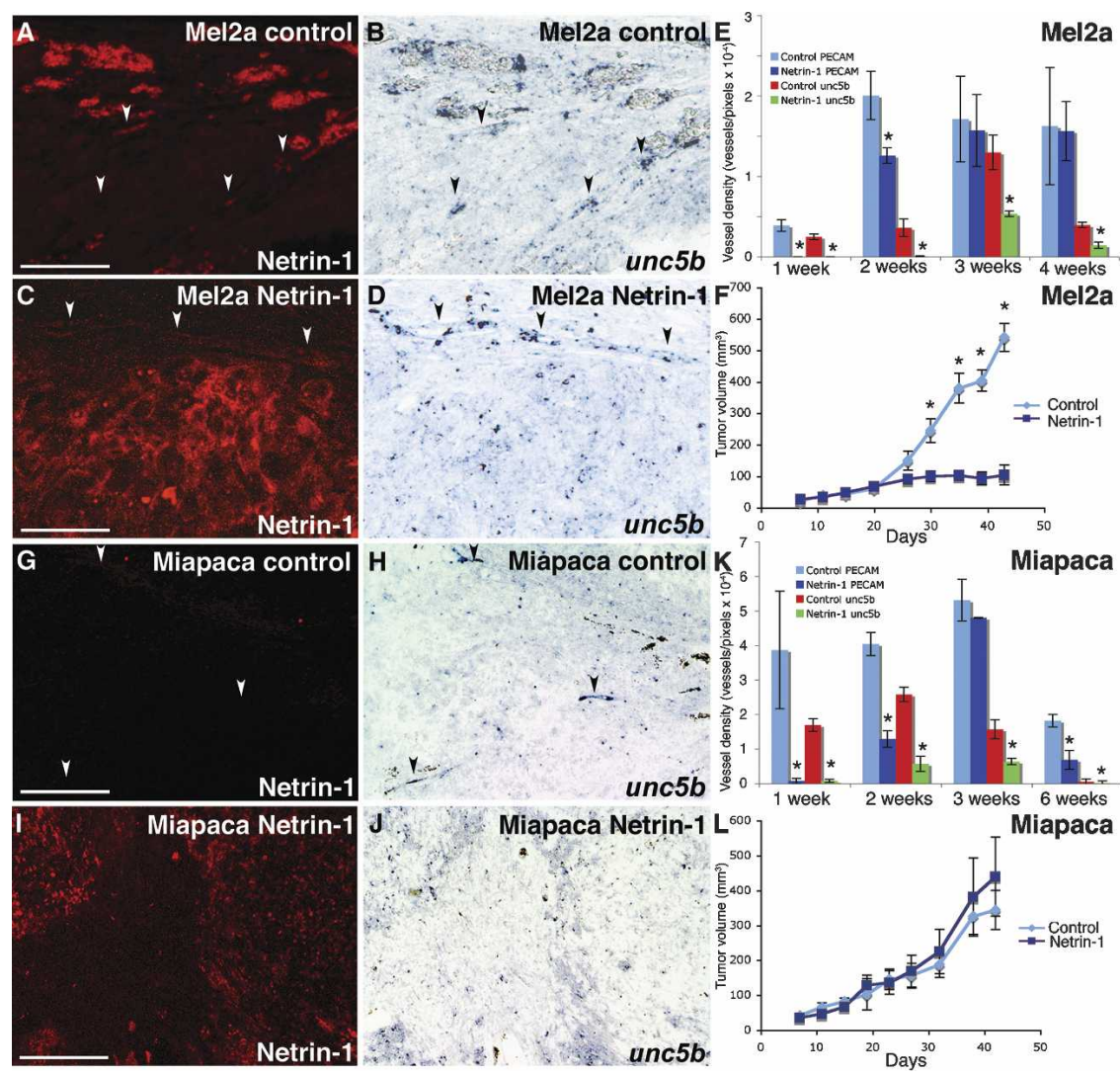

Figure 7. Netrin-1 overexpression reduces sprouting of unc $5 b$-expressing vessels and delays tumor angiogenesis. $(A, B)$ Mel2a control tumor 4 wk post-implantation. (B) Representative section hybridized with an antisense riboprobe against unc $5 b$ showing expression on sprouting vessels invading the tumor (blue, arrowheads). (A) Netrin-1 immunostaining (red) of the same section. Note absence of immunoreactivity in control tumor tissue. Red staining is due to background immunofluorescence of erythrocytes contained in blood vessels. $(C, D)$ Mel2a Netrin-1-overexpressing tumor 3 wk post-implantation. Note that unc $5 b$-positive vessels (blue, arrowheads) avoid Netrin-1-positive tumor areas. (E) Quantification of PECAM-1positive and unc5b-positive blood vessels per surface area of the tumor in control and Netrin-1-overexpressing Mel2a tumors. (F) Growth curve of Mel2a tumor xenografts implanted in the dorsa of NMRI $n u / n u$ mice. $n=10$ mice per group. $(G, H)$ Miapaca control tumor 6 wk postimplantation. Note unc $5 b$-positive sprouts (blue, arrowheads) in the Netrin-1-negative tumor tissue. $(I, J)$ Miapaca Netrin-1overexpressing tumor 6 wk post-implantation. Note absence of unc5b-positive sprouts in Netrin-1-overexpressing tumor tissue. $(K)$ Quantification of PECAM-1positive and unc $5 b$-positive blood vessels per surface area in control and Netrin-1-overexpressing Miapaca tumors. $(L)$ Growth curves of Miapaca tumor xenografts implanted in the dorsa of NMRI nu/nu mice. $n=10$ mice per group. Data in $E$ and $K$ represent the quantification of two or three tumors per group and three to five sections per tumor. Error bars: SEM; $\left(^{\star}\right) P<0.05$, Mann-Whitney $U$-test. Bars: $A-D, 70 \mu \mathrm{m} ; G-I, 125 \mu \mathrm{m}$.

trigel experiments (Fig. 8G,H). Comparison of control vector and Netrin-1-transduced PC3 tumors implanted into homozygous unc $5 b$ mutant mice showed no significant difference in vascularized area between Netrin-1 and control-transduced tumor cells (Fig. 8C,D), and the sprouting inhibition induced by Netrin-1 was silenced (Fig. 8I,J). Thus, Netrin-1 inhibits tumor angiogenic sprouting via UNC5B.

\section{Discussion}

We found that expression of the unc $5 b$ receptor during postnatal and pathological angiogenesis is restricted to vessels undergoing active angiogenic sprouting. While adult, quiescent vessels were unc $5 b$ negative, re-expression was observed during sprouting angiogenesis induced by OIR and matrigel or tumor implantation. Re-expression of unc $5 b$ mRNA in neovessels recapitulates the embryonic expression pattern of this receptor (Lu et al. 2004), with high levels seen in arteries and capillary sprouts and lower levels in veins. Interestingly, neovascularization following femoral artery ligation did not lead to endothelial unc $5 b$ re-expression, suggesting that this form of angiogenesis, which may not require extensive sprouting, can occur in the absence of UNC5B and that UNC5B may be preferentially required during sprouting angiogenesis. Unc $5 b$ transcription is thus part of the active angiogenesis process, although the precise molecular mechanisms regulating its transcription remain to be determined.

Sprouting angiogenesis was reduced after activation of the UNC5B receptor by its ligand Netrin-1. Live imaging in aortic ring assays demonstrated that unc $5 b$-expressing capillary sprouts respond to Netrin-1 stimulation by retraction. Sprouts derived from $u n c 5 b^{-/-}$mice lose response to Netrin-1. No conversion of repulsion to attraction was observed in the absence of UNC5B in these experiments. Similarly, Netrin-1 alone showed no proangiogenic activity in matrigel plugs but potently inhibited bFGF-induced neovessel sprouting. Examination of Netrin receptor mRNA levels in matrigel plugs showed the presence of unc5b mRNA, but the absence of $d c c$ (Nguyen and Cai 2006) and very low levels of neogenin. The presence of repulsive, but not attractive, receptors is consistent with the observed inhibitory Netrin-1 effect. Moreover, Netrin-1-induced inhibition of neovascularization was reduced in unc $5 b^{-/-}$mice, indicating a requirement for UNC5B. Taken together, these data suggest that activation of UNC5B during sprouting angiogenesis triggers repulsive responses of these vessels. 

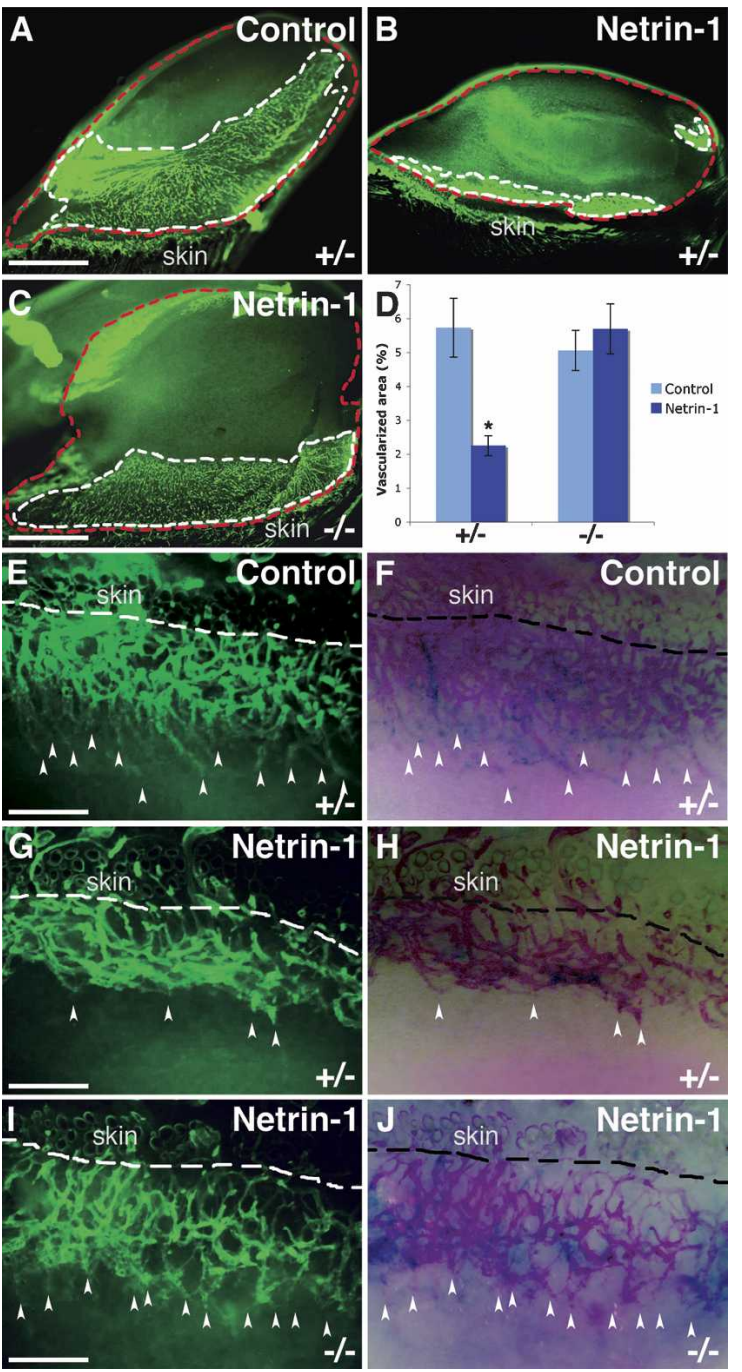

Figure 8. Netrin-1-induced inhibition of tumor vessel sprouting requires UNC5B. $(A-C)$ Whole-mount Collagen-IV staining of thick sections from PC3 control $(A)$ and Netrin-1-overexpressing $(B, C)$ tumors implanted into unc $5 b$ heterozygous $(A, B)$ and homozygous $(C)$ mutant mice. The tumor nodule forming beneath the skin is outlined (dashed, red). Vessels invading the tumor are outlined (dashed, white). Vascular area within the tumors is reduced by Netrin- 1 in unc $5 b$ heterozygous $(B)$ compared with control $(A)$, but not homozygous mutant $(C)$, mice. $(D)$ Computer-assisted quantification of vascular area in tumor nodules. $n=3$ tumors per group; four thick sections per tumor (corresponding to the entire tumor) were photographed and quantified. $(E-J)$ Higher magnifications of vessels sprouting from the skin into the tumor area. $(E, G, I)$ Whole mounts were double-stained with Collagen-IV and X-gal. In the overlays shown in $F, H$, and $J$, Collagen-IV staining appears as purple color on the dark-blue X-gal staining. Note double-positive vessels (arrowheads) sprouting into control PC3 tumors $(F)$, blunted appearance of vessel sprouts in Netrin-1-overexpressing tumors implanted into unc5b heterozygous mice $(H)$, and restored sprouting when Netrin-1-overexpressing tumors are implanted into unc $5 b$ homozygous mutant mice $(J)$. Error bars: SEM; $\left({ }^{\star}\right)$ $P<0.05$, Mann-Whitney $U$-test. Bars: $A-C, 800 \mu \mathrm{m} ; E-I$, $130 \mu \mathrm{m}$.
Determining the localization of the endogeneous UNC5B ligand(s) during postnatal and adult life will establish the physiological relevance of UNC5B signaling during sprouting angiogenesis. This signaling pathway could be part of a negative feedback mechanism to ensure appropriate vessel patterning and to prevent excessive vessel sprouting. A similar negative feedback mechanism involves the endothelial Notch ligand Deltalike 4 (Dll4) (Hellstrom et al. 2007; Lobov et al. 2007; Suchting et al. 2007). Dll4, expressed on endothelial tip cells, binds to Notch receptors on adjacent stalk cells, preventing these cells from also forming sprouts by reducing their response to VEGF. Notch and UNC5B signaling may thus both contribute to angiogenic homeostasis. Alterations in unc5b expression in d114 mouse mutants (Suchting et al. 2007) suggest a link of these pathways that remains to be fully investigated.

UNC5B could mediate repulsive signaling in response to Netrin-1 directly or, alternatively, be part of a signaling complex involving one or more coreceptor(s). We tested these possibilities using PAECs. Native PAECs fail to respond to Netrin-1 in sprouting and proliferation assays. When transfected with UNC5B FL, but not $\Delta \mathrm{CD}$ constructs, these cells respond to recombinant Netrin-1 by reduced sprouting and repulsion. Coculture of Netrin1-producing tumor cells with UNC5B FL, but not $\Delta \mathrm{CD}$ cells, led to segregation of the two populations over time, clearly indicating a repulsive effect of Netrin-1 mediated by UNC5B signaling. As the extracellular domain of UNC5B can bind Netrin-1 (Hong et al. 1999; data not shown), these results indicate that UNC5B is sufficient to directly mediate Netrin-1 responses in PAECs. Deletion of the cytoplasmic domain of UNC5B abolished the repulsive response to Netrin-1, indicating that this domain is required to trigger downstream signaling events that remain to be fully elucidated (Round and Stein 2007).

Expression of the UNC5B ligands netrin-1 and netrin-3 in 20 different human tumor cell lines was low, while many of these cell lines expressed the related netrin-4, which, however, does not bind UNC5B (see above and Wilson et al. 2006). There are, as yet, few studies of netrin expression in human cancer; however, two studies describe down-regulation of netrin-1 in prostate tumors (Latil et al. 2003) and in a subset of brain tumors and neuroblastomas (Meyerhardt et al. 1999) compared with normal healthy prostate or brain tissue. These data are consistent with the idea that invasive sprouting of blood vessels into tumors is facilitated in the absence of UNC5B ligands, although a more comprehensive investigation of human tumors is required. They are also consistent with our finding that Netrin-1 overexpression in tumor cells led to inhibition of sprouting of unc5b-expressing neovessels and delayed tumor angiogenesis. Inhibition of neovascularization was most pronounced during the initial stages of tumor invasion and likely mediated by UNC5B, as Netrin-1-overexpressing and control tumors implanted into unc5b-deficient mice exhibited similar vascularization. Inhibition of vascularization in Netrin-1-overexpressing tumors up to 2 wk 
post-implantation led to significant tumor hypoxia (data not shown), presumably inducing high levels of VEGF expression, which could explain why at later stages postimplantation tumor vessel density between Netrin-1overexpressing and control-transduced tumors reached comparable levels. As only their sprouting was inhibited in the presence of Netrin-1, tumor vessels may switch to other types of growth such as circumferential growth or intussusception (Augustin 2001).

Our results clearly show that UNC5B functions as a receptor for Netrin-1 in vivo, confirming and extending previous studies (Leonardo et al. 1997; Hong et al. 1999; Lu et al. 2004). It remains to be determined if Netrin-1 represents the (only) relevant in vivo ligand for UNC5B in mice. In zebrafish embryos, MO-mediated knockdown of unc5b or netrin-1a led to increased filopodial extensions and aberrant vessel branching of intersegmental vessels (ISV) (Lu et al. 2004). We have repeated knockdowns using the splice-blocking MO reported by Wilson et al. (2006). We find that we can fully recapitulate our previous result; i.e., aberrant ISV branching from the dorsal aorta (Supplementary Fig. 7; Supplementary Movie 5). Our data in zebrafish are thus consistent with netrin-1a as a negative regulator of vessel branching. However, the results reported here do not exclude a possible proangiogenic role of Netrin-1. Nonendothelial cells in the ischemic area expressing unc $5 b$ (and perhaps other Netrin receptors) could respond to Netrin-1 and perhaps contribute to ischemic revascularization. In addition, we have not observed endothelial unc5b expression following femoral artery ligation, and stimulation of UNC5B-negative endothelial cells by Netrin-1 could elicit proangiogenic responses. The present study provides multiple lines of evidence indicating that repulsive responses following Netrin-1 stimulation are consistently observed during neovascularization processes where unc $5 b$ is expressed, including tumor angiogenic sprouting. Development of UNC5B-selective agonists may be considered as potential therapeutic tools in antiangiogenic strategies.

\section{Materials and methods}

Animals

CD1 unc5b LacZ-plap mice were described previously (Lu et al. 2004) and genotyped with the following modifications: primers unc $5 b$ wild-type forward, 5'-TGGTGAGAATTTTGGATTG CAGGC-3', and reverse, 5'-GAGAGGAGAGCAACGGATGT GAC-3'; mutant forward, 5'-TCGGTGCACATGCTTTACGT GTGT-3', and reverse, 5'-ATGAGCTGCGTAGCGATGTCC TG-3', using $6 \mathrm{pmol}$ of each in a $25-\mu \mathrm{L}$ PCR reaction $\left(95^{\circ} \mathrm{C} / 25\right.$ sec, $\left.62^{\circ} \mathrm{C} / 30 \mathrm{sec}, 72^{\circ} \mathrm{C} / 55 \mathrm{sec}\right) \times 35$ cycles. C57Bl6 mice were obtained from Charles River Laboratories. NMRI nu/nu mice were obtained from Elevage Janvier and housed in sterile conditions.

\section{Immunohistochemistry and in situ hybridization}

For X-gal or AP whole-mount immunostaining, tissues were dissected, washed in PBS, fixed for $10 \mathrm{~min}$ at room temperature in $4 \% \mathrm{PAF}$, rinsed in $\mathrm{PBS}$, and incubated at $37^{\circ} \mathrm{C}$ with $\mathrm{X}$-gal staining solution (Lu et al. 2004) or at $65^{\circ} \mathrm{C}$ for $1 \mathrm{~h}$ and subsequently at $37^{\circ} \mathrm{C}$ in AP developing buffer as described (Leighton et al. 2001). Whole-mount immunohistochemistry of retinas was done as described (Suchting et al. 2007), using biotinylated IsolectinB $\mathrm{B}_{4}$ (Vector). Images were taken using a Leica TCS SP2 confocal microscope or an Olympus fluorescence microscope. For immunostaining of paraffin or cryostat sections, the following antibodies were used: anti-PECAM-1 (BD Pharmingen), antiNetrin-1 (R\&D), anti-CD45 (Biolegend), and anti-Phospho-Histone-H3 (Abcam), followed by Alexa 488- or Alexa 555-conjugated secondary antibodies (Molecular Probes), HRP-conjugated secondary antibodies, or tyramide signal amplification using a TSA kit (PerkinElmer). Nuclei were stained by incubating sec-

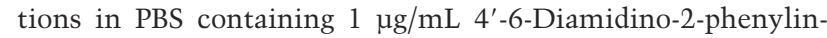
dole (DAPI; Sigma) for 5 min. For histological analysis of tumors, sections were stained with hematoxylin and eosin (H\&E).

For in situ hybridization on paraffin sections (Lu et al. 2004), proteinase $\mathrm{K}$ treatment $(6 \mu \mathrm{g} / \mathrm{mL})$ was done for $7 \mathrm{~min}$ at $37^{\circ} \mathrm{C}$ and a 1-kb fragment of rat unc5b (nucleotides 200-1271) was used as a riboprobe. Images were taken using an Olympus microscope.

\section{PCR}

For RT-PCR, total cellular RNA was extracted from tumor cells or matrigel plugs using RNAble (Eurobio) according to the manufacturer's instructions. Three micrograms of purified total RNA were used as a template to generate first strand cDNA using Moloney murine leukemia virus reverse transcriptase (Invitrogen). PCR was performed using the following primer pairs: human A2b, 5'-CTATGCTTACCGGAACCGAG-3' and 5'-AC CATGCCCGGCCGAATAAT-3'; human DCC, 5' -AACACTC TCAGTGGACCGAG- ${ }^{\prime}$ and $5^{\prime}$-TCCTTAACTGAGTGGTCC TG-3'; human Neogenin, 5'-CTCCTATGCCAGTGGTTGTT$3^{\prime}$ and $5^{\prime}$-CAACCACTTGTGGAGAACAC-3'; human Netrin1, 5'-CCGAGTCCATGGCCATCTAC-3' and 5'-ATCTGGAC GGCATAGTCCTT-3'; human Netrin-3, 5'-TTGAGCTGGT CTTCGTGAGC-3' and 5'-TTTGCAGTGCGAGTCACAGT-3'; human Netrin-4, 5'-TGTGTAAGCACAACACAGCAGGC-3' and 5'-AAGAGCTGGTTTCCAGTGCTGG-3'; human Unc5A, 5'-AGCTGTCCCTTAATGCTGGT-3' and 5'-AAGGCTGTG TACATAAGGCC-3'; human Unc5B, 5' -TGGCACATACCCT AGCGATT-3' and 5'-AGTAATTCAGGTACCGGTCC-3'; human Unc5C, 5'-ATTTGCCGCTGCTGGATCCT-3' and 5'-AC AACAAACCGTCCACAGCT-3'; human Unc5D, 5'-GCCTC GAGTACTTGGTAAGT-3' and 5'-TGTGTCATTCTCTGTAG GCC-3'; mouse A2b, 5'-CTACTTTCTGGTATCCCTGG-3' and 5'-CTCGGTTCCTGTAGGCATAG-3'; mouse DCC, 5'AACGCTGTCTGTGGACCGAG-3' and 5'-GTTGCTTCATT AGCCCTTCC-3'; mouse Neogenin, 5'-TCAGATGATCGAC GCCAGCT-3' and 5'-GTCCCAGCATCATCCTCAGT-3'; mouse Netrin-1, 5' -CAGAGTCCATGGCCATCTAC-3' and 5'ATCTGGACAGCATAGTCCTT-3'; mouse Netrin-3, 5'-TTG AGCTGGTCTTCGTGAGC-3' and 5'-TCTGCAATGTGACT CACAGT-3'; mouse Netrin-4, 5' -TGTGTAAGCACAACACA GCAGGC-3' and 5'-AAGAGCTGGTTTCCAGTGCTGG-3'; mouse Unc5A, 5'-GCTTCCAGCCTGTCAGCATC-3' and 5'AGAGCATCGTGGGTGTCGTG-3'; mouse Unc5B, 5' -GGGC ACGTACCCAGGCGATT-3' and 5'-CGAAGTAGTTTAGG TACCGGTCC-3'; mouse Unc5C, 5'-TAACCTGAAGAACCA GAGCC-3' and 5'-AGGGTCCAGGAGAGGTAAGT-3'; mouse Unc5D, 5'-ATTGAGAATGCCAGCGACAT-3' and 5'-TGTC CACACAGTAAACTCTC-3'; human and mouse tubulin, 5'GCTTCAAGGTTGGCATCAAC-3' and 5'-TAGTATTCCTCT CCTTCTTC-3'. Amplification was carried out with an iCycler (Bio-Rad) $\left[\left(95^{\circ} \mathrm{C} / 2 \mathrm{~min}\right),\left(95^{\circ} \mathrm{C} / 25 \mathrm{sec}, 57^{\circ} \mathrm{C} / 5 \mathrm{sec}, 68^{\circ} \mathrm{C} 5\right.\right.$ $\min ) \times 32$ or $\left.40,\left(72^{\circ} \mathrm{C} / 10 \mathrm{~min}\right)\right]$. 
For qPCR, retinal endothelial cells were isolated from P5 and P60 CD1 mice as described (Suchting et al. 2007), with the following modifications: Cells were incubated for $20 \mathrm{~min}$ at $4{ }^{\circ} \mathrm{C}$ with rat anti-mouse-PECAM-1 (BD Pharmingen) (5 $\mu \mathrm{g})$, and endothelial cells were separated with sheep anti-rat IgG magnetic beads (Dynabeads). QPCR was performed in an iCycler RealTime PCR detection system (Bio-Rad) using SYBR Green PCR master mix (Qiagen) and the thermocycler conditions recommended by the manufacturer. PCRs were performed in triplicate using $1 \mu \mathrm{L}$ of cDNA in a total volume of $25 \mu \mathrm{L}$. Each sample was analyzed for $\beta$-actin to normalize for RNA input and PECAM-1 to normalize for endothelial cell gene expression. Primers were as follows: mouse unc $5 b, 5^{\prime}$-GAGTGGCTATGCTTGTGATT TGG-3' and 5'-CATAGCAAAGCCTTTCCCTGTG-3'; mouse Pecam-1, 5'-CAAGCAAAGCAGTGAAGCTG- ${ }^{\prime}$ and $5^{\prime}$-TC TAACTTCGGCTTGGGAAA-3'; mouse $\beta$-actin, $5^{\prime}$-TGTTAC CAACTGGGACGACA-3' and 5'-GGGGTGTTGAAGGTCT CAAA-3'. Melting curve analysis showed a single sharp peak with the expected $T m$ for all samples.

\section{Matrigel plug experiments}

Ice-cold matrigel (BD) was mixed with PBS, $0.2 \%$ BSA, bFGF $(\mathrm{R} \& D)$, and/or mouse Netrin-1 (R\&D) and kept on ice. Mice were anesthetized with ketamine/Rompun, and $500 \mu \mathrm{L}$ of matrigel was injected subcutaneously at the base of the tail. After 2 wk, mice were killed by sodium pentobarbital (Centravet) injection and the matrigel plugs were removed and either stained with X-gal or homogenized in $500 \mu \mathrm{L}$ of $20 \mathrm{mM}$ Tris $(\mathrm{pH}$ 7.2 ), and $0.9 \% \mathrm{NH}_{4} \mathrm{Cl}$ at $4{ }^{\circ} \mathrm{C}$. Tubes were centrifuged and hemoglobin concentration was determined on two $50-\mu \mathrm{L}$ samples using Drabkin solution (Sigma). For VEGFR-2 ELISA, samples homogenized as described above were mixed with $100 \mu \mathrm{L}$ of $5 \times$ RIPA buffer containing protein cocktail inhibitor (Sigma), vortexed, and incubated overnight at $4{ }^{\circ} \mathrm{C}$. Tubes were centrifuged for $30 \mathrm{~min}$ at $5000 \mathrm{rpm}$ and the supernatant was analyzed using ELISA assay $(R \& D)$ for mouse VEGFR-2 according to the manufacturer's instructions. For staining of perfused vessels, IsolectinB $_{4}$-Alexa 568 (Invitrogen) was injected in the tail vein of pentobarbital-anesthetized mice. After $2 \mathrm{~min}$, the right auricle was cut, then $2.5 \mathrm{~mL}$ of PBS were injected into the right ventricle followed by the injection of $2.5 \mathrm{~mL}$ of $\mathrm{PBS} 1 \% \mathrm{PAF}$ $0.5 \%$ glutaraldehyde. Matrigel plugs were removed, embedded in OCT (Tissue-Tek), and frozen. Forty-micron sections $(n=5$ sections per plug, 3 plugs bFGF, 2 bFGF plus Netrin-1 $300 \mathrm{ng} /$ $\mathrm{mL}, 1 \mathrm{bFGF}$ plus Netrin-1 $1 \mu \mathrm{g} / \mathrm{mL}$ ) were analyzed by confocal microscopy (Leica).

\section{Hindlimb ischemia}

Femoral artery ligation on C57/BL6 mice was performed on three mice as described (Luttun et al. 2002), and triple-ligation excision of femoral arteries from unc5b lacZ-plap mice (Cazes et al. 2006) was done with four mice analyzed $2 \mathrm{~d}$ after ligation and four mice at $5 \mathrm{~d}$ following ligation.

\section{Aortic ring assay}

Dorsal aortas from embryonic day $11.5 u n c 5 b^{+/+}, u n c 5 b^{+/-}$, and unc $5 b^{-1-}$ embryos (total of 21 embryos, six different litters) were surgically removed, cut in several rings, and cultured either in rat tail collagen (Roche) $(n=6+/+, 12+/-, 7-/-)$ or matrigel $(n=5+/-, 9-/-)$. Rat tail collagen was reconstituted in $0.2 \%$ acetic acid and the gel prepared by mixing $8 \mu \mathrm{L} \mathrm{NaHCO}, 12 \mu \mathrm{L}$ $10 \times \mathrm{MEM}$, and $80 \mu \mathrm{L}$ collagen. Ice-cold matrigel was diluted $1 / 2$ in complete PBS. A $50-\mu \mathrm{L}$ drop of the gel was added to a Petri dish and allowed to solidify for $30 \mathrm{~min}$ at $37^{\circ} \mathrm{C}$ in a humidified $\mathrm{CO}_{2}$ incubator. Aortic explants were put on top of the gel, covered with a $20-\mu \mathrm{L}$ drop of gel, and incubated another $30 \mathrm{~min}$ to solidify. Supplemented ECGM2 (Promocell) was added and the explants were cultured for $48 \mathrm{~h}$. Chicken Netrin-1 (R\&D) gradients were applied to the aortic endothelial sprouts using a glass micropipette. Individual sprouts $(n=6+/+, 17+/-, 16-/-)$ were imaged by time-lapse videomicroscopy for $2 \mathrm{~h}$ under an inverted microscope (Leica). Filopodial length of individual tips was measured using Metamorph software.

\section{Constructs}

The FL rat unc5b cDNA in pMT21 vector was recloned in pCDNA3,1A(-) vector (Invitrogen) in-frame with the myc/his tag with the following primers to add restriction sites and mutate the stop codon: 5'-GCTCTAGAGAGGGCCCGGAGCGG GGCGCGGG-3' and 5'-CGGAATTCTGCAATCGCCATCAG TGGTCATGGC-3'. The UNC5B construct corresponding to the 424 first amino acids and without most of the cytoplasmic part $(\Delta \mathrm{CD})$ was obtained by restriction digest of the FL construct by $\mathrm{XbaI}$ and HincII. Both FL and $\Delta \mathrm{CD}$ constructs were inserted in pEGFP-N1 vector (Clontech) in-frame with the GFP sequence.

A FL human netrin-1 cDNA was cloned by RT-PCR using oligo-dT(23)VN-primed human embryo polyA-RNA (Clontech; $100 \mathrm{ng}$ ) and RNA SuperScript III (Clontech; $200 \mathrm{U}$ ) followed by PCR amplification of $1 / 10$ of the $\mathrm{RT}$ reaction $\left[95^{\circ} \mathrm{C} / 2 \mathrm{~min}\right.$, $\left.\left(95^{\circ} \mathrm{C} / 18 \mathrm{sec}, 68^{\circ} \mathrm{C} / 8 \mathrm{~min}\right) \times 35,72^{\circ} \mathrm{C} / 10^{\circ} \mathrm{C}\right]$ using Pfu DNA polymerase (Promega; $1.5 \mathrm{U}$ ) with $10 \mathrm{pmol}$ of the following primers: forward, 5'-TCTAGATGGACGCAGCATGATGCGC GCAGTGT-3'; reverse, 5' -GGTACCAGGCCTTTCTTGCACT TGCCCTTCTTCTC-3'. PCR product was gel-purified, adapted to a pCRII-TOPO cloning vector (Invitrogen) after 20 min treatment at $72^{\circ} \mathrm{C}$ with TaqII (NEB), and sequenced. XbaI-KpnI digestion of this vector was cloned into pcDNA3.1myc-his. $H$ netrin-1 with the myc and his tags was then cloned in the retroviral vector MSCVneo (Clontech).

\section{PAE cell assays}

UNC5B FL or $\triangle$ CD PAECs were seeded on eight-well slides (BD) coated with fibronectin at a concentration of 10,000 cells per well or in fibronectin-coated two-well Lab-tek chambered coverglasses (Nunc) $(80,000$ cells per well) for time-lapse videomicroscopy. The next day, PAECs were incubated with recombinant Netrin-1 (R\&D) $(0,10,100,500 \mathrm{ng} / \mathrm{mL})$ for $30 \mathrm{~min}(10$ experiments with duplicates for each Netrin-1 concentration) or with recombinant mouse Netrin-4 or Netrin-1 (300 ng/mL) for time-lapse videomicroscopy.

For sprouting assays, gelatin-coated microcarrier beads (Cytodex 3; Sigma) were incubated with PAECs. When the cells reached confluence on the beads, equal numbers of PAECcoated beads were embedded in fibrin gels in 96-well plates. For preparation of fibrin gels, bovine fibrinogen $(2.5 \mathrm{mg} / \mathrm{mL}$; Sigma $)$ was dissolved in Dulbecco's modified eagle medium (DMEM)/ $10 \%$ FBS. Aprotinin $(0.05 \mathrm{mg} / \mathrm{mL}$; Sigma) was added, and the solution was filtered through a 0.22 - $\mu \mathrm{m}$ pore-size filter. In some cases, fibrinogen solution was supplemented with mouse Netrin-1 $(300 \mathrm{ng} / \mathrm{mL})$. Following transfer of the fibrinogen solution to 96-well plates, PAEC-coated beads were added at a density of 50 beads per well, and clotting was induced by the addition of thrombin $(1.2 \mathrm{U} / \mathrm{mL}$ ) (Sigma). Following $60 \mathrm{~min}$ of incubation, DMEM/10\% FBS, either alone or containing 300 ng/mL Netrin1 , was added to the wells. After $24 \mathrm{~h}$, the number of capillarylike tubes formed was quantitated using Metamorph software. 
For coculture experiments, transfected PAECs $(20,000$ cells per well) were plated onto eight-well slides in complete DMEM. The next day, vector control or Netrin-1-expressing tumor cells were stained with PKH26 dye (Sigma) according to the manufacturer's instructions, and 20,000 cells per well were added to the wells previously seeded with PAECs. Two hours to $24 \mathrm{~h}$ later, slides were washed in PBS, fixed in $4 \%$ PAF for 5 min, mounted in polyvinyl alcohol mounting medium, and visualized by confocal microscopy.

\section{Cells and retroviral transduction}

Tumor cells, PT67 retroviral packaging cells (Clontech), and PAECs were cultured in DMEM supplemented with 10\% FBS (Gibco-Invitrogen) and penicillin-streptomycin (Gibco-Invitrogen). PAECs were transfected with UNC5B FL or $\triangle \mathrm{CD}$ constructs using Fugene-6 (Roche) according to the manufacturer's instructions. Stably transfected clones were selected using G418 $(1.2 \mathrm{mg} / \mathrm{mL})$ for $14 \mathrm{~d}$. For each construct, one clone that exhibited strong uniform fluorescence at the surface of all cells was selected for further analysis and expanded. For generation of amphotropic packaged virus, PT67 packaging cells were transfected with MSCVneo-Netrin-1 using Fugene-6. Cell selection was done with $500 \mu \mathrm{g} / \mathrm{mL}$ G418 $48 \mathrm{~h}$ after transfection. Drugresistant cells were then expanded and subcultured. For retroviral infection of tumor cells, supernatant was harvested from stably transfected PT67 cells, filtered, and used for repeated infections of tumor cells in the presence of $8 \mu \mathrm{g} / \mathrm{mL}$ polybrene (Sigma). After 48 h, retrovirally infected cells were selected using $700 \mu \mathrm{g} / \mathrm{mL}$ G418. For all experiments, cells transduced with the empty vector MSCVneo were used as controls. Numerous aliquots were frozen, and the same batch of infected cells was used for all experiments.

\section{Determination of the level of hNetrin-1 expression in transduced tumor cells}

Tumor cells were grown for $48 \mathrm{~h}$ in serum-free DMEM, lysed in buffer containing $1 \%$ NP-40, $0.5 \%$ sodium deoxycholate, and $0.1 \%$ sodium dodecyl sulfate (SDS), with addition of fresh protease inhibitor cocktail (Sigma). Supernatant $(7 \mathrm{~mL}$ ) was concentrated using an Amicon Ultra Centrifugal Device (Millipore). Twenty microliters of $500-\mu \mathrm{L}$ concentrated supernatant were separated by SDS-PAGE, transferred to PVDF membranes (Millipore), and developed by enhanced chemiluminescence (PerkinElmer). For solid phase receptor assay, concentrated supernatants were incubated overnight at $4^{\circ} \mathrm{C}$ in ELISA plates coated with anti-human IgG1 $(1.8 \mu \mathrm{g} / \mathrm{mL}$; Jackson laboratories), saturated with $\mathrm{PBS} / 1 \% \mathrm{BSA}$, then coated with $200 \mathrm{ng} / \mathrm{mL}$ UNC5B/Fc chimera (R\&D). Plates were washed in Tris-buffered saline (TBS) $/ 0.05 \%$ Tween 20 (Sigma) and incubated for $2 \mathrm{~h}$ with anti-His-HRP (Roche). After further washes, plates were incu-

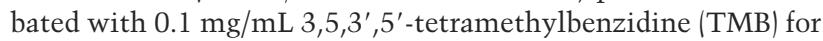
15 min and stopped by addition of $1 \mathrm{M} \mathrm{H}_{2} \mathrm{SO}_{4}$. Absorbance at $450 \mathrm{~nm}$ was read on a microplate reader (Dynatech MR5000) with wavelength correction set at $540 \mathrm{~nm}$.

\section{BrdU incorporation}

Subconfluent cells grown on microscope slides (BD) for $48 \mathrm{~h}$ were labeled for $2 \mathrm{~h}$ with $10 \mu \mathrm{M}$ BrdU (Sigma). Cells were fixed with $4 \%$ PAF for $5 \mathrm{~min}$, washed with PBS, and permeabilized with ice-cold methanol for $1 \mathrm{~min}$. Slides were then incubated for $20 \mathrm{~min}$ at $37^{\circ} \mathrm{C}$ with $2 \mathrm{~N} \mathrm{HCl}$, blocked in PBS, 5\% goat serum, and $0.1 \%$ Triton X-100 for $10 \mathrm{~min}$, followed by a 1 -h incubation with primary antibody (anti-BrdU conjugated with
Alexa Fluor 594; Molecular Probes). After washing, nuclear DNA was stained with $1 \mu \mathrm{g} / \mathrm{mL}$ DAPI, and slides were mounted in anti-fading solution (Fluka).

\section{Proliferation assays}

Tumor cells were seeded on 96-well plates at a density of 5000 cells per well. At various time points, viable cell numbers were estimated by incubating with fresh media containing $25 \mu \mathrm{g} / \mathrm{mL}$ neutral red for $3 \mathrm{~h}$. Neutral red is a chromogenic vital dye that is actively transported into the lysosome of viable cells. The cellular dye uptake is proportional to the number of viable cells. Incorporated dye was solubilized by addition of $100 \mu \mathrm{L}$ of $50 \%$ $(\mathrm{v} / \mathrm{v})$ ethanol, $1 \%(\mathrm{v} / \mathrm{v})$ acetic acid in DDW. The plates were read at $550 \mathrm{~nm}$ in a microplate reader. Optic density at $550 \mathrm{~nm}$ is directly proportional to the number of viable cells in the sample.

Endothelial cells (HUVEC or HUAEC; Promocell) were seeded on 96-well plates at a density of 1000 cells per well precoated with collagen-1 (BD) in EBM (Clonetics) containing $0.3 \%$ FBS. After $24 \mathrm{~h}$, cells were stimulated with recombinant mouse Netrin-1 (R\&D) or human VEGF 165 (R\&D) every day for $3 \mathrm{~d}$. Twenty-four hours after the third stimulation, cell quantity was measured with CellTiter-Glo (Promega) and luminescence was analyzed with a Fusion plate reader (Packard).

PAECs were seeded on a 96-well plate at 5000 cells per well in DMEM/0.3\% FBS and analyzed as above.

\section{Soft agar colony-forming assay}

One-thousand-five-hundred cells from each tumor cell line were placed onto six-well plates in DMEM containing 0.35\% agar overlying a $0.7 \%$ agar layer. The cells were cultured for 14 $\mathrm{d}$ and photographed (three or four representative pictures per well).

\section{Tumor xenografts}

Tumor cells $\left(5 \times 10^{6}\right.$ per mouse $)$ were harvested, mixed with an equal volume of Matrigel, and injected in the right dorsa of 4- to 6-wk-old nude mice (NMRI nu/nu; 10 mice per group). The experiment was repeated with a second group of five mice per transduced cell line, with similar results. Tumor size was determined by caliper measurements and tumor volume was calculated by a rational ellipse formula (length $\times$ width $\times$ depth $\times 0.5236)$. Mice were sacrificed after the tumor grew to $\approx 500 \mathrm{~mm}^{3}$. Tumors were excised, weighed, fixed in $4 \% \mathrm{PAF}$, and processed for paraffin embedding. For tumor xenografts into CD1 unc5b LacZ-plap mice, $5 \times 10^{6}$ PC3 control and Netrin-1 cells were resuspended in serum-free DMEM and implanted in the right (control) and left (Netrin-1) dorsa of mice.

\section{Statistical analysis}

A two-tailed Mann-Whitney $U$-test was used for quantification of aortic ring assays, tumor growth, blood vessel counts of matrigel plugs, and measurements of cocultures. All countings were done by two independent observers blinded to the experimental conditions. Dunnett's test was used for the VEGFR-2 concentrations. A Kruskal-Wallis test was used for hemoglobin concentrations. $P<0.05$ was considered statistically significant.

\section{Zebrafish analysis}

Tg(fli1:EGFP)y ${ }^{1}$ zebrafish (Lawson and Weinstein 2002) were maintained under standard laboratory conditions. The follow- 
ing morpholino oligonucleotide targeting netrin-1a was purchased from GeneTools LLC): 5'-ATGATGGACTTACCGAC ACATTCGT-3' (Wilson et al. 2006). Different doses (7.2, 9, and $10.8 \mathrm{ng}$ ) of morpholino were injected into single- to four-cell stage zebrafish embryos, using procedures described previously (Stalmans et al. 2003). Between 30 and 60 injected embryos were analyzed per experiment from $20 \mathrm{~h}$ post-fertilization (hpf) to 72 hpf to identify alterations in sprouting of intersegmental vessels and in the formation of the parachordal vessel of the trunk region. Each experiment was repeated at least three times. The penetrance of the phenotype was scored by counting the affected embryos. Images of $\mathrm{Tg}(f l i 1: E G F P)^{\mathrm{y} 1}$ embryos were acquired with a Zeiss CLSM510 META NLO camera installed on an inverted AxioVert 200M microscope (Zeiss) equipped with a 1.5-W pulsed Ti:Sa Chameleon laser (Coherent) at minimum laser output.

\section{Acknowledgments}

We acknowledge Coralie Lebouvier and Thomas Mathivet for their contribution to this manuscript. This work was supported by grants from INSERM, Ministère de la Recherche (ANRPCOD, ANR Neuroscience), ARC (3124), Institut de France (Cino del Duca), and the European Community (LSHG-CT2004-503573 to A.E. and P.C.). B.L. is supported by the Ligue Nationale contre le Cancer. C.F. is supported by a fellowship from the Fundação para a Ciência e a Tecnologia, MCTES, Portugal.

\section{References}

Ackerman, S.L., Kozak, L.P., Przyborski, S.A., Rund, L.A., Boyer, B.B., and Knowles, B.B. 1997. The mouse rostral cerebellar malformation gene encodes an UNC-5-like protein. Nature 386: 838-842.

Augustin, H.G. 2001. Tubes, branches, and pillars: The many ways of forming a new vasculature. Circ. Res. 89: 645-647.

Baluk, P., Morikawa, S., Haskell, A., Mancuso, M., and McDonald, D.M. 2003. Abnormalities of basement membrane on blood vessels and endothelial sprouts in tumors. Am. I. Pathol. 163: 1801-1815.

Benimetskaya, L., Wittenberger, T., Stein, C.A., Hofmann, H.P., Weller, C., Lai, J.C., Miller, P., and Gekeler, V. 2004 Changes in gene expression induced by phosphorothioate oligodeoxynucleotides (including G3139) in PC3 prostate carcinoma cells are recapitulated at least in part by treatment with interferon- $\beta$ and $-\gamma$. Clin. Cancer Res. 10: 3678 3688.

Carmeliet, P. and Tessier-Lavigne, M. 2005. Common mechanisms of nerve and blood vessel wiring. Nature 436: 193200

Cazes, A., Galaup, A., Chomel, C., Bignon, M., Brechot, N., Le Jan, S., Weber, H., Corvol, P., Muller, L., Germain, S., et al. 2006. Extracellular matrix-bound angiopoietin-like 4 inhibits endothelial cell adhesion, migration, and sprouting and alters actin cytoskeleton. Circ. Res. 99: 1207-1215.

Chan, S.S., Zheng, H., Su, M.W., Wilk, R., Killeen, M.T., Hedgecock, E.M., and Culotti, J.G. 1996. UNC-40, a C. elegans homolog of DCC (Deleted in Colorectal Cancer), is required in motile cells responding to UNC-6 netrin cues. Cell 87: 187-195.

Cirulli, V. and Yebra, M. 2007. Netrins: Beyond the brain. Nat. Rev. Mol. Cell Biol. 8: 296-306.

Colamarino, S.A. and Tessier-Lavigne, M. 1995. The axonal chemoattractant netrin-1 is also a chemorepellent for trochlear motor axons. Cell 81: 621-629.

Dickson, B.J. 2002. Molecular mechanisms of axon guidance. Science 298: 1959-1964.

Eichmann, A., Makinen, T., and Alitalo, K. 2005. Neural guidance molecules regulate vascular remodeling and vessel navigation. Genes \& Dev. 19: 1013-1021.

Fazeli, A., Dickinson, S.L., Hermiston, M.L., Tighe, R.V., Steen, R.G., Small, C.G., Stoeckli, E.T., Keino-Masu, K., Masu, M., Rayburn, H., et al. 1997. Phenotype of mice lacking functional Deleted in colorectal cancer (Dcc) gene. Nature 386: 796-804.

Gariano, R.F. and Gardner, T.W. 2005. Retinal angiogenesis in development and disease. Nature 438: 960-966.

Gerhardt, H., Golding, M., Fruttiger, M., Ruhrberg, C., Lundkvist, A., Abramsson, A., Jeltsch, M., Mitchell, C., Alitalo, K., Shima, D., et al. 2003. VEGF guides angiogenic sprouting utilizing endothelial tip cell filopodia. J. Cell Biol. 161: $1163-1177$.

Hedgecock, E.M., Culotti, J.G., and Hall, D.H. 1990. The unc-5, unc- 6 , and unc-40 genes guide circumferential migrations of pioneer axons and mesodermal cells on the epidermis in $C$. elegans. Neuron 4: 61-85.

Hellstrom, M., Phng, L.K., Hofmann, J.J., Wallgard, E., Coultas, L., Lindblom, P., Alva, J., Nilsson, A.K., Karlsson, L., Gaiano, N., et al. 2007. Dll4 signalling through Notch1 regulates formation of tip cells during angiogenesis. Nature 445: 776780.

Hong, K., Hinck, L., Nishiyama, M., Poo, M.M., Tessier-Lavigne, M., and Stein, E. 1999. A ligand-gated association between cytoplasmic domains of UNC5 and DCC family receptors converts netrin-induced growth cone attraction to repulsion. Cell 97: 927-941.

Keino-Masu, K., Masu, M., Hinck, L., Leonardo, E.D., Chan, S.S., Culotti, J.G., and Tessier-Lavigne, M. 1996. Deleted in Colorectal Cancer (DCC) encodes a netrin receptor. Cell 87: 175-185.

Keleman, K. and Dickson, B.J. 2001. Short- and long-range repulsion by the Drosophila Unc5 netrin receptor. Neuron 32: 605-617.

Kleinman, H.K. and Martin, G.R. 2005. Matrigel: Basement membrane matrix with biological activity. Semin. Cancer Biol. 15: 378-386.

Koch, M., Murrell, J.R., Hunter, D.D., Olson, P.F., Jin, W., Keene, D.R., Brunken, W.J., and Burgeson, R.E. 2000. A novel member of the netrin family, $\beta$-netrin, shares homology with the $\beta$ chain of laminin: Identification, expression, and functional characterization. J. Cell Biol. 151: 221-234.

Latil, A., Chene, L., Cochant-Priollet, B., Mangin, P., Fournier, G., Berthon, P., and Cussenot, O. 2003. Quantification of expression of netrins, slits and their receptors in human prostate tumors. Int. J. Cancer 103: 306-315.

Lawson, N.D. and Weinstein, B.M. 2002. In vivo imaging of embryonic vascular development using transgenic zebrafish. Dev. Biol. 248: 307-318.

Leighton, P.A., Mitchell, K.J., Goodrich, L.V., Lu, X., Pinson, K., Scherz, P., Skarnes, W.C., and Tessier-Lavigne, M. 2001. Defining brain wiring patterns and mechanisms through gene trapping in mice. Nature 410: 174-179.

Leonardo, E.D., Hinck, L., Masu, M., Keino-Masu, K., Ackerman, S.L., and Tessier-Lavigne, M. 1997. Vertebrate homologues of C. elegans UNC-5 are candidate netrin receptors. Nature 386: 833-838.

Leung-Hagesteijn, C., Spence, A.M., Stern, B.D., Zhou, Y., Su, M.W., Hedgecock, E.M., and Culotti, J.G. 1992. UNC-5, a transmembrane protein with immunoglobulin and thrombo- 
spondin type 1 domains, guides cell and pioneer axon migrations in C. elegans. Cell 71: 289-299.

Lobov, I.B., Renard, R.A., Papadopoulos, N., Gale, N.W., Thurston, G., Yancopoulos, G.D., and Wiegand, S.J. 2007. Deltalike ligand 4 (Dll4) is induced by VEGF as a negative regulator of angiogenic sprouting. Proc. Natl. Acad. Sci. 104: 3219-3224.

Lu, X., Le Noble, F., Yuan, L., Jiang, Q., De Lafarge, B., Sugiyama, D., Breant, C., Claes, F., De Smet, F., Thomas, J.L., et al. 2004. The netrin receptor UNC5B mediates guidance events controlling morphogenesis of the vascular system. Nature 432: 179-186.

Luttun, A., Tjwa, M., Moons, L., Wu, Y., Angelillo-Scherrer, A., Liao, F., Nagy, J.A., Hooper, A., Priller, J., De Klerck, B., et al. 2002. Revascularization of ischemic tissues by PlGF treatment, and inhibition of tumor angiogenesis, arthritis and atherosclerosis by anti-Flt1. Nat. Med. 8: 831-840.

Meyerhardt, J.A., Caca, K., Eckstrand, B.C., Hu, G., Lengauer, C., Banavali, S., Look, A.T., and Fearon, E.R. 1999. Netrin-1: Interaction with deleted in colorectal cancer (DCC) and alterations in brain tumors and neuroblastomas. Cell Growth Differ. 10: 35-42.

Nguyen, A. and Cai, H. 2006. Netrin-1 induces angiogenesis via a DCC-dependent ERK1/2-eNOS feed-forward mechanism. Proc. Nat1. Acad. Sci. 103: 6530-6535.

Olsson, A.K., Dimberg, A., Kreuger, J., and Claesson-Welsh, L. 2006. VEGF receptor signalling - In control of vascular function. Nat. Rev. Mol. Cell Biol. 7: 359-371.

Round, J. and Stein, E. 2007. Netrin signaling leading to directed growth cone steering. Curr. Opin. Neurobiol. 17: 15-21.

Serafini, T., Colamarino, S.A., Leonardo, E.D., Wang, H., Beddington, R., Skarnes, W.C., and Tessier-Lavigne, M. 1996. Netrin-1 is required for commissural axon guidance in the developing vertebrate nervous system. Cell 87: 1001-1014.

Shibuya, M. 2006. Differential roles of vascular endothelial growth factor receptor-1 and receptor-2 in angiogenesis. $I$. Biochem. Mol. Biol. 39: 469-478.

Smith, L.E., Wesolowski, E., McLellan, A., Kostyk, S.K., D'Amato, R., Sullivan, R., and D'Amore, P.A. 1994. Oxygeninduced retinopathy in the mouse. Invest. Ophthalmol. Vis. Sci. 35: 101-111.

Stalmans, I., Lambrechts, D., De Smet, F., Jansen, S., Wang, J., Maity, S., Kneer, P., von der Ohe, M., Swillen, A., Maes, C., et al. 2003. VEGF: A modifier of the del22q11 (DiGeorge) syndrome? Nat. Med. 9: 173-182.

Suchting, S., Freitas, C., le Noble, F., Benedito, R., Breant, C., Duarte, A., and Eichmann, A. 2007. The Notch ligand Deltalike 4 negatively regulates endothelial tip cell formation and vessel branching. Proc. Natl. Acad. Sci. 104: 3225-3230.

Van Raay, T.J., Foskett, S.M., Connors, T.D., Klinger, K.W., Landes, G.M., and Burn, T.C. 1997. The NTN2L gene encoding a novel human netrin maps to the autosomal dominant polycystic kidney disease region on chromosome 16p13.3. Genomics 41: 279-282.

Wang, H., Copeland, N.G., Gilbert, D.J., Jenkins, N.A., and Tessier-Lavigne, M. 1999. Netrin-3, a mouse homolog of human NTN2L, is highly expressed in sensory ganglia and shows differential binding to netrin receptors. I. Neurosci. 19: 4938-4947.

Wilson, B.D., Ii, M., Park, K.W., Suli, A., Sorensen, L.K., LarrieuLahargue, F., Urness, L.D., Suh, W., Asai, J., Kock, G.A., et al. 2006. Netrins promote developmental and therapeutic angiogenesis. Science 313: 640-644.

Yin, Y., Sanes, J.R., and Miner, J.H. 2000. Identification and expression of mouse netrin-4. Mech. Dev. 96: 115-119. 


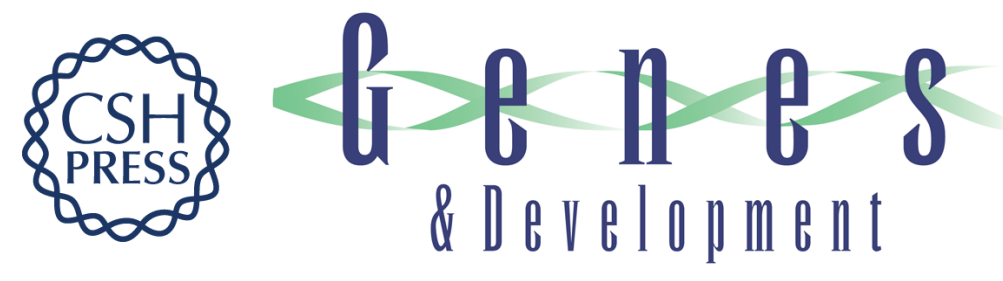

\section{Activation of the UNC5B receptor by Netrin-1 inhibits sprouting angiogenesis}

Bruno Larrivée, Catarina Freitas, Marc Trombe, et al.

Genes Dev. 2007, 21:

Access the most recent version at doi:10.1101/gad.437807

Supplemental
Material http://genesdev.cshlp.org/content/suppl/2007/10/01/21.19.2433.DC1

References This article cites 42 articles, 14 of which can be accessed free at: http://genesdev.cshlp.org/content/21/19/2433.full.html\#ref-list-1

License

Email Alerting

Receive free email alerts when new articles cite this article - sign up in the box at the top Service right corner of the article or click here.

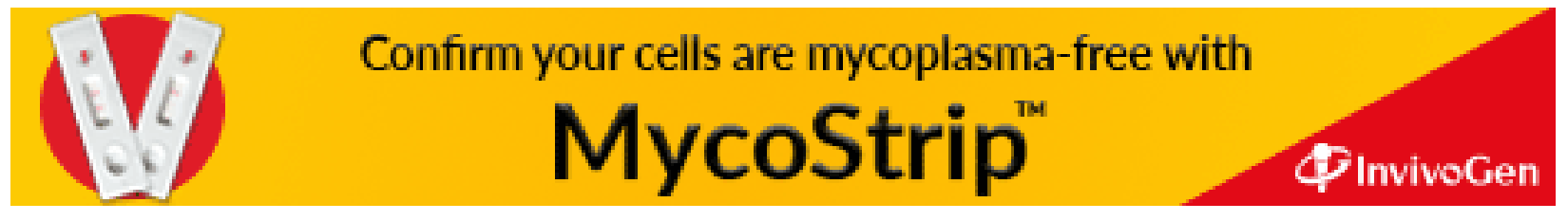

